\title{
Novel players and large-scale protein dynamics of BCR activation revealed by APEX2 proximity labelling of lipid rafts
}

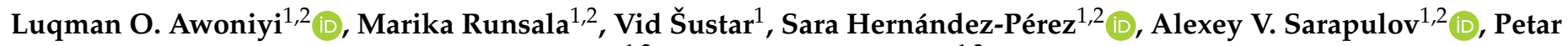 \\ Petrov $^{1,2}$ iD and Pieta K. Mattila ${ }^{1,2, *}$ iD \\ ${ }^{1}$ Institute of Biomedicine and MediCity Research Laboratories, University of Turku, Turku, Finland \\ 2 Turku Bioscience, University of Turku and Åbo Akademi University, Turku, Finland \\ *Correspondence: pieta.mattila@utu.fi
}

Successful B cell activation, critical for high-affinity antibody production, is controlled by the B cell antigen receptor (BCR). While the main components of the BCR signalling machinery are relatively well characterised, we still lack a comprehensive protein-level view of the very dynamic multibranched cellular events triggered by antigen binding. In this study, we pioneer usage of APEX2 proximity biotinylation for studying antigen receptor signalling. APEX2 provides critical spatial and kinetic resolution, $20 \mathrm{~nm}$ and $1 \mathrm{~min}$, to trace early protein dynamics upon antigen engagement. We identified a total of 1677 proteins to locate in the vicinity of APEX2 at the plasma membrane lipid raft domains, where the BCR translocates upon activation. Our data provides unprecedented insights into the composition of lipid raft environment in B cells and the dynamic changes triggered upon BCR cross-linking. The data provides new understanding into the behaviour of proteins known to be involved in the proximal antigen receptor signalling, and the simultaneously triggered processes, such as actin cytoskeleton remodelling and endocytosis. Interestingly, our differential enrichment analysis identified dynamic responses in various proteins that have not previously been linked to early B cell activation. We validated Golga3 and Vti1b as novel proteins responding to BCR activation, confirming that our dataset serves as a valuable tool for future studies.

Immunology | B cells | BCR I antigen receptor I receptor signalling I lipid rafts I proximity proteomics | Vti1b | Golga3 I APEX2

\section{Introduction}

B lymphocytes constitute a critical branch of the adaptive immune system by differentiating into antibody producing plasma cells after recognition of specific antigens via their signature B cell receptor (BCR). BCR signalling is a robust trigger that leads to detectable phosphorylation of, for instance, the downstream kinases and structural cellular processes, like actin cytoskeleton reorganisation and internalisation of the BCR, within minutes of activation. Numerous studies on BCR signalling have sketched a picture of a multi-branched signalling network that triggers not only the signalling cascades to change the transcriptional program but also other cellular machineries such as cytoskeleton reorganisation, endocytosis and vesicle transport, as well as protein degradation (Harwood \& Batista, 2010; Kuokkanen et al., 2015; Kwak et al., 2019). Coordinated engagement of such a vast variety of, often interlinked, cellular pathways have challenged our understanding of the early events of B cell activation. One of the major limitations has been the inability to study the combinations of cellular changes broadly, yet with sufficient spatial and temporal resolution. An efficient way to analyse the signalling network and to identify novel players in given cellular pathways is proteomics.
Quantitative mass spectrometry (MS)-based proteomics has previously been employed to study BCR signalling. For instance, Satpathy and colleagues used affinity purification to study the dynamics of BCR interactions upon stimulation with biotinylated anti-IgG $\mathrm{F}\left(\mathrm{ab}^{\prime}\right)_{2}$ at different time points(Satpathy et al., 2015). However, the sample preparation for traditional proteomic approaches, relying on co-immunoprecipitations or organelle purification, occurs in the test tube and, thus, poses significant challenges in capturing weak or transient protein interactions (Qin et al., 2021). In recent years, proximity labelling techniques have become a powerful tool for mapping protein-protein interactions in the native cellular environment. These techniques include antibody-based approaches, such as EMARS and SPPLAT, the promiscuous biotin ligases BioID/BirA*, the engineered ascorbate peroxidases APEX, and the variants thereof (Bosch et al., 2021; Samavarchi-Tehrani et al., 2020; Qin et al., 2021). Proximitybased techniques are typically based on in cellulo biotinylation triggered by enzymes, tagged to a compartment or protein of interested, that generate short-lived biotin radicals that mark their immediate molecular environment. Of these techniques, only SPPLAT (selective proteomic proximity labelling using tyramide) has been suc- 
cessfully applied to the study of BCR interactions, using anti-IgM-HRP antibodies to capture the proteins proximal to the BCR clusters in the chicken B cell line DT40 ( $\mathrm{Li}$ et al., 2014). However, because SPPLAT relies on subjecting living cells to HRP-conjugated antibodies, the biotinylation is thus restricted mainly to the extracellular side of the plasma membrane, failing to capture the whole complexity of processes triggered inside the cell. BioID and APEX2, on the other hand, have a biotinylation radius of $10-20 \mathrm{~nm}$ and they have been successfully used to identify both specific protein interactomes as well as protein environments in various intracellular compartments, such as the mitochondrial matrix, mitochondrial intermembrane space and primary cilia (Bareja et al., 2018; Hung et al., 2014; Mick et al., 2015; Rhee et al., 2013; Roux et al., 2012; Bosch et al., 2021). The second generation version of APEX, APEX2, that achieves efficient biotinylation in 1 minute, is to date the fastest and most efficient labelling enzyme (Hung et al., 2016; Lam et al., 2015). In contrast, TurboID, the fastest member of the BioID family, requires 5-10 min (Chen \& Perrimon, 2017; Doerr, 2018). Therefore, the fast labelling kinetics enabled by APEX2 makes it truly powerful in capturing signalling events with high dynamics, such as receptor signalling. For example, APEX2 was recently used in a tour de force of tracking GPCR signalling and internalisation with high spatial resolution (Paek et al., 2017). However, as for any other fusion protein, expression of APEX2 as a fusion partner of a particular signalling protein can prove technically challenging and also potentially compromise the protein function. In such a scenario, targeting the enzyme to the cellular compartment of interest could provide a better readout. Upon antigen binding, BCR is known to translocate from fluid, detergent-soluble plasma membrane domains to less fluid, detergent-resistant cholesterol/sphingolipidrich membrane domains, called lipid rafts, for signalling and internalisation (Aman \& Ravichandran, 2000; Cheng et al., 1999; Gupta et al., 2006; Sohn et al., 2006; Núñez et al., 2020; Sedwick \& Altman, 2002; Stone et al., 2017; Varshney et al., 2016). This transition provides a spatial window for utilizing proximity biotinylation to study BCR signalling. In the past, B cell lipid rafts have been isolated for proteomic analysis via cell fractionation methods (Gupta et al., 2006; Mielenz et al., 2005; Saeki et al., 2003). However, the challenging nature of the biochemical fractionation is illustrated by the limited protein identification, with reported protein numbers in these studies varying between 18 and 39. Here, we pioneer the use of APEX2 for tracking the cellular events occurring in B cells after BCR activation with high spatial and temporal resolution. We utilised the well-defined translocation of the BCR to the lipid rafts in order to capture the signalling events and immediate cellular responses at 5,10 or $15 \mathrm{~min}$ after BCR engagement, with a 1-min resolution window as allowed by APEX2. Our data, containing 1677 high-confidence hits, provides an encyclopaedia of the proteins locating at the B cell plasma membrane and the lipid rafts, while at the same time, revealing the dynamics therein induced by BCR stimulation. We identify a wealth of previously uncharacterised proteins responding to the BCR stimulation and also verify the translocation of two of them, Golga3 and Vti1b, towards activated and internalised BCR indicating novel machineries in early antigen vesicle transport.

\section{Results}

Validation of a $B$ cell line expressing lipid rafttargeted APEX2. In order to gain novel, spatiotemporal information about the immediate cellular responses to BCR activation, we decided to employ a proximity labelling enzyme, APEX2, capable of promiscuously biotinylating proteins within a $20 \mathrm{~nm}$ range with a 1-min temporal resolution. As BCR is known to translocate to the lipid raft regions of the plasma membrane upon activation (Aman \& Ravichandran, 2000; Cheng et al., 1999; Gupta et al., 2006; Sohn et al., 2008, 2006; Stone et al., 2017; Varshney et al., 2016), we decided to fuse APEX2 with a specific 7 amino acid lipidation sequence, MGCVCSS, to target it to the lipid raft domains (Fig.1A). The MGCVCSS sequence contains one myristoylation (Gly-2) and two Sacylation sites (Cys-3 and Cys-5) for palmitoylation, originally identified in the NH2-terminus of Lck, to the NH2terminus of APEX2. These modifications are responsible for the localisation of Lck to the lipid rafts (Yasuda et al., 2000) and it has been shown to be able to target fusion proteins to the membrane, and to the immunological synapse of T cells (Bécart et al., 2008; Bi et al., 2001). In addition, we equipped our APEX2 construct with an mCherry fluorescent protein to facilitate the detection of APEX2 expression and generated the final raft-APEX2 construct (Fig.1A, zoom inset).

Next, we transfected raft-APEX2 into cultured A20 B cells, that stably expressed transgenic hen egg lysozyme (HEL)-specific D1.3 IgM BCR (A20 D1.3) (Aluvihare et al., 1997), and generated a stable A20 D1.3 raft-APEX2 cell line. The flow cytometry analysis confirmed that mCherry $+/$ IgM+ cells composed $>99 \%$ of the resulting cell line (data not shown). To confirm that raftAPEX2 indeed localises to the plasma membrane, we analysed its localisation using AiryScan confocal microscopy (Huff, 2015) to gain sufficient resolution to unambiguously detect signals deriving from the B cell plasma membrane. Raft-APEX2 clearly colocalised with the membrane marker, wheat germ agglutinin (WGA), demonstrating strong enrichment at the plasma membrane (Fig.1B). The lipid raft domains in resting cells are typically very small 
bioRxiv preprint doi: https://doi.org/10.1101/2020.09.29.318766; this version posted March 5, 2021. The copyright holder for this preprint

(which was not certified by peer review) is the author/funder, who has granted bioRxiv a license to display the preprint in perpetuity. It is made APEX2 proximity proteomics of B cell activation available under aCC-BY-ND 4.0 International license.

A
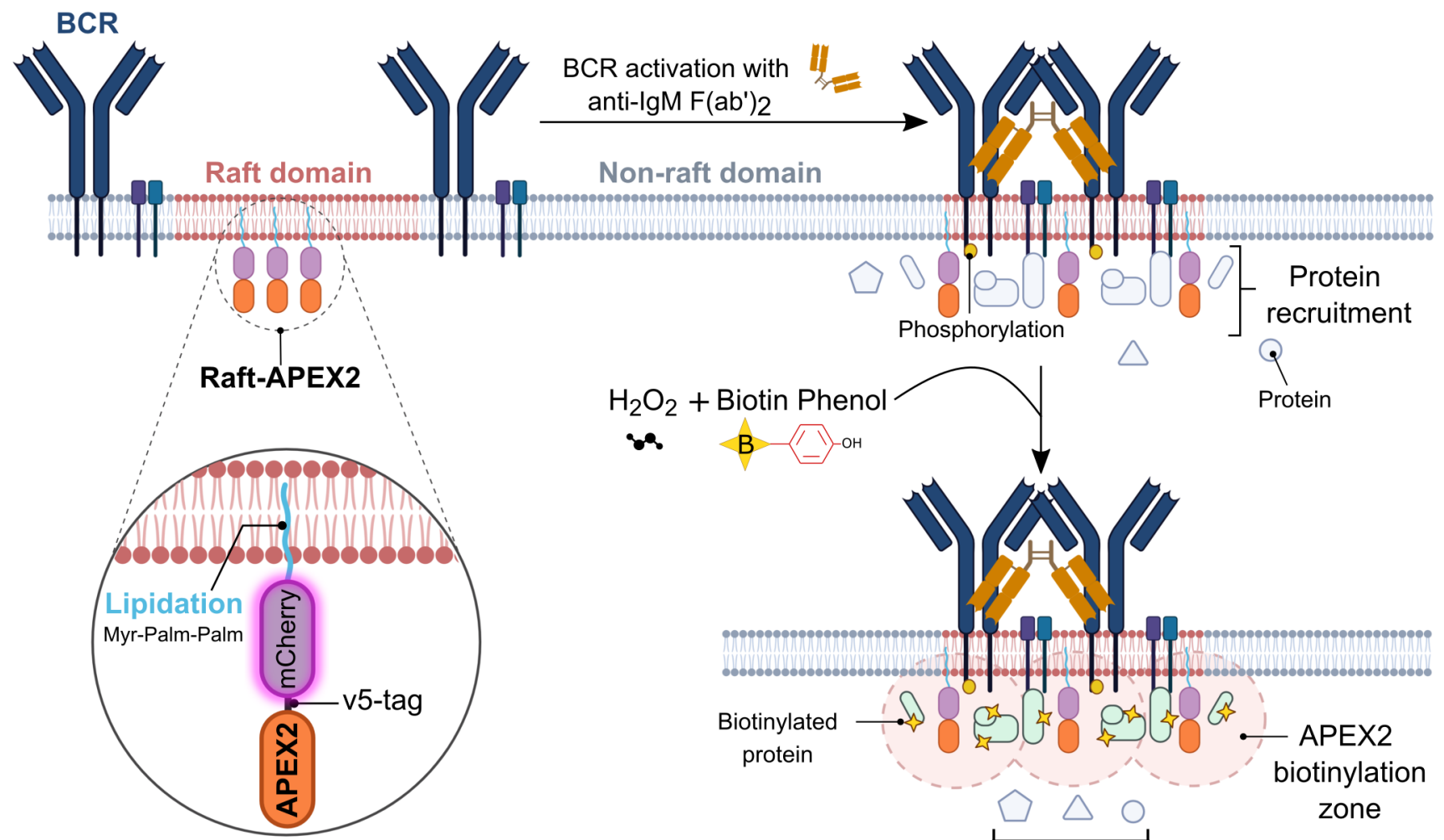

se. $\mathrm{B}<\mathrm{CO}$
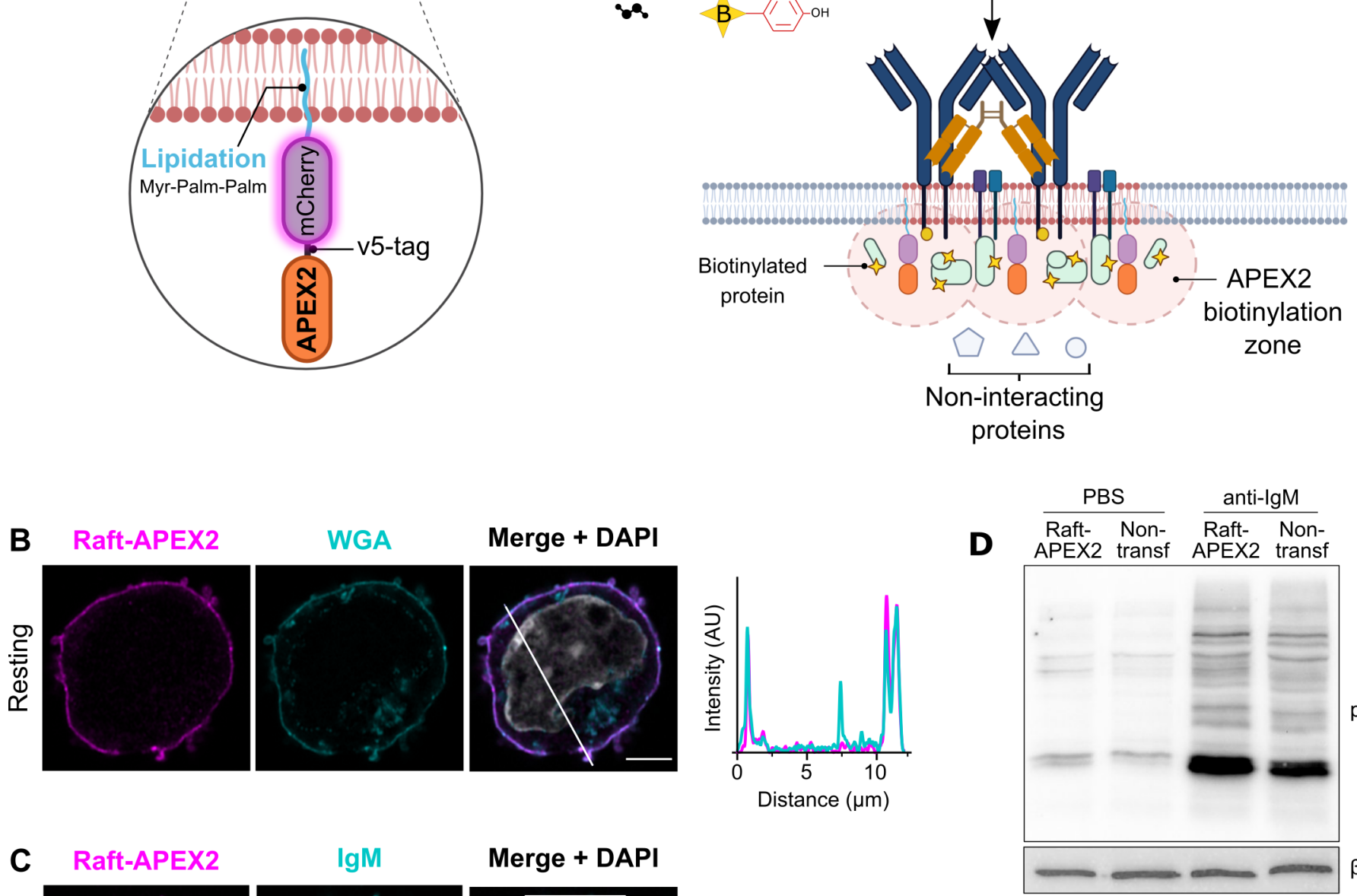

pTyr
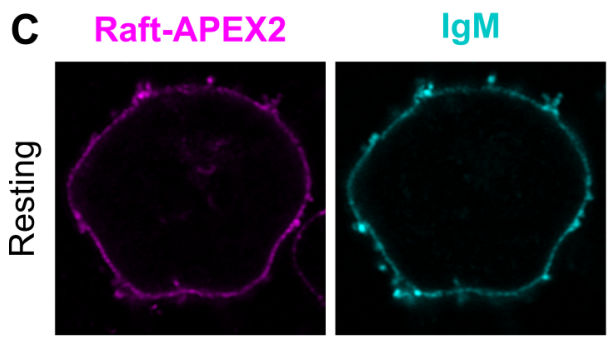

Merge + DAPI
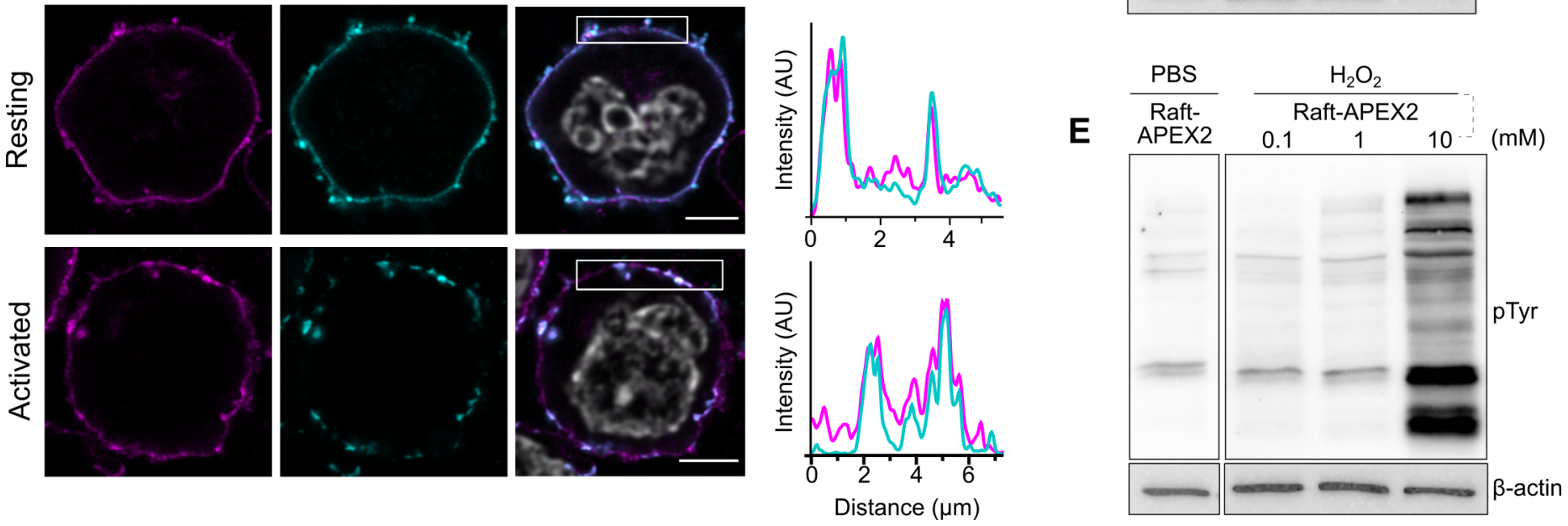

Figure 1: Targeting of APEX2 to the lipid rafts to study B cell activation: design and validation. A) Schematic illustration of the raft-APEX2-mediated proximity biotinylation as a read out of BCR signalling response. MPP-mCherry-APEX2 (raft-APEX2) (Continued) 
bioRxiv preprint doi: https://doi.org/10.1101/2020.09.29.318766; this version posted March 5, 2021. The copyright holder for this preprint

(which was not certified by peer review) is the author/funder, who has granted bioRxiv a license to display the preprint in perpetuity. It is made APEX2 proximity proteomics of B cell activation available under aCC-BY-ND 4.0 International license.

Figure 1: (Continued) construct is targeted to the lipid raft membrane domains, where also BCR translocates upon activation, and where it induces biotinylation of proteins in the $<20 \mathrm{~nm}$ range in a $1 \mathrm{~min}$ time window. The technique allows identification and label-free quantification of proteins proximal to the lipid rafts at different time points of BCR activation. B) A20 D1.3 B cells expressing raft-APEX2 were settled on a fibronectin-coated glass coverslips for $1 \mathrm{~h}$ prior to fixation. Cells were stained with WGA as a membrane marker and DAPI for nucleus. Left: Airyscan super-resolution confocal microscopy was used to image mCherry to visualise raft-APEX2 (magenta), WGA-Atto488 (cyan) and DAPI (grey, merge). Right: line scan analysis of the colocalisation of raft-APEX2 and WGA. C) A20 D1.3 B cells expressing raft-APEX2 were settled on a fibronectin-coated glass coverslips for $1 \mathrm{~h}$, activated (bottom panel) or not (upper panel; resting) by addition of $1 \mu \mathrm{g}$ of HEL for $5 \mathrm{~min}$, and fixed. The samples were stained for IgM and DAPI was used to label the nucleus. Airyscan super-resolution confocal microscopy was used to image mCherry to visualise raft-APEX2 (magenta), IgM (cyan) and DAPI (grey, merge). Right: box scan analysis of the colocalisation of raft-APEX2 and IgM. D) Parental (non-transfected) and raft-APEX2expressing A20 D1.3 B cells were stimulated with $10 \mu \mathrm{g}$ of anti-IgM F $\left.(\mathrm{ab})^{\prime}\right)_{2}$ for $10 \mathrm{~min}$ and subjected to Western blotting. The membranes were probed with HRP-anti phospho-Tyrosine antibodies, and anti / beta-actin as a loading control. E) Raft-APEX2 expressing A20 D1.3 B cells were treated with $0,0.1,1$ and $10 \mathrm{mM} \mathrm{H}_{2} \mathrm{O}_{2}$ for $1 \mathrm{~min}$. Cells were lysed and subjected to Western blotting as in D. See Suppl. Fig.S1C for the uncropped image corresponding to D and E.

and transient in nature, making their detection highly challenging even with modern microscopy techniques (Gupta \& DeFranco, 2003; Sezgin et al., 2017; Stone et al., 2017). Upon activation, BCR forms clusters that are rich in signalling activity and, at the same time, represent larger detergent-resistant membrane domains (Gupta $\mathcal{E}$ DeFranco, 2003; Mattila et al., 2016; Stone et al., 2017). Thus, we next activated the IgM BCR by HEL antigen and followed the colocalisation of IgM with raft-APEX2. As expected, upon cell activation, we detected increased clustering of the IgM as well as enrichment of APEX2 in the same structures (Fig.1C), indicative for localisation of the raft-APEX2 probe in the IgM signalling clusters. To investigate the membrane domain localisation of raft-APEX2 in more detail, a flow cytometry-based assay was adopted (Gombos et al., 2004). We expressed raft-APEX2 in A20 D1.3 cells together with model proteins resident either at lipid raft (GPI-DAF-GFP) (Legler et al., 2005) or detergentsoluble membrane domains (TDM-GFP) (Nikolaus et al., 2010). In this assay, the cells were treated with $0.1 \%$ Triton X-100 to release the detergent-soluble proteins from the plasma membrane and a detergent resistance index was calculated based on the fluorescence before and after detergent treatment (Suppl. Fig.S1A). The analysis showed a considerable fraction of raft-APEX2 resisting the detergent treatment although slightly less than the GPI anchored model protein (Suppl. Fig.S1B). The detergentsoluble model protein TDM-GFP, on the other hand, was almost completely removed from the plasma membrane after detergent incubation. We also stained the cells with non-stimulatory Fab fragments of anti-IgM antibodies to label the BCR, which was then activated or not using the model antigen HEL. Consistent with previous studies (Aman \& Ravichandran, 2000; Cheng et al., 1999; Gupta et al., 2006; Gupta E DeFranco, 2003; Sohn et al., 2006, 2008; Stone et al., 2017), we saw IgM substantially shifting towards detergent-resistant membrane domains upon cell activation. This analysis provided important support to our approach to use lipid raft-preferring raft-APEX2 as a proxy to label proteins enriched at the vicinity of signalling BCRs. We then proceeded to test for possible negative effects caused by the expression of raft-APEX2 in our system. We found normal levels of IgM BCR in our raft-APEX2 cell line and the BCR was internalised at normal kinetics upon receptor stimulation (data not shown). Upon BCR-activation the cells showed indistinguishable levels of phosphorylation, detected by antiphospho-Tyrosine antibodies, as compared to the parental cell line (Fig.1D and Suppl. Fig.S1C). Triggering of the biotinylation activity of APEX2 requires addition of $\mathrm{H}_{2} \mathrm{O}_{2}$. Notably, $\mathrm{H}_{2} \mathrm{O}_{2}$ has been shown to inhibit protein phosphatases and thereby to be able to trigger signalling (Reth, 2002; Wienands et al., 1996). However, we detected no increase in general protein phosphorylation upon incubation of cells with $1 \mathrm{mM} \mathrm{H} \mathrm{H}_{2} \mathrm{O}_{2}$ for $1 \mathrm{~min}$, the conditions used to trigger biotinylation by APEX2, while ten times higher concentration of $\mathrm{H}_{2} \mathrm{O}_{2}$ induced profound signalling, consistent with previous reports (Reth, 2002) (Fig.1E and Suppl. Fig.S1C). This data suggests that there is no significant unspecific phosphorylation occurring in $\mathrm{B}$ cells caused by the $\mathrm{H}_{2} \mathrm{O}_{2}$ addition to the reaction.

Proteomic analysis For preparing the proximity biotinylation samples, biotin-phenol supplemented cells were activated with potent surrogate antigen, $\mathrm{F}\left(\mathrm{ab}^{\prime}\right)_{2}$ fragments of anti-IgM antibodies for $0,5,10$ or $15 \mathrm{~min}$ (Fig.2A). The biotinylation was triggered by addition of $1 \mathrm{mM} \mathrm{H}_{2} \mathrm{O}_{2}$ and quenched with addition of Trolox after $1 \mathrm{~min}$. The efficiency of biotinylation was verified in each set of samples by flow cytometric analysis, which typically showed biotinylation in $\approx 70 \%$ of cells (Suppl. Fig.S1D). Lysed cells were subjected to streptavidin affinity purification to pull down the biotinylated proteins for mass spectrometry (MS) analysis (Fig.2B). To control for the possible baseline activity of the APEX2 and the levels of endogenous biotinylation, samples without $\mathrm{H}_{2} \mathrm{O}_{2}$ or without biotin-phenol were prepared, respectively. All conditions were performed in triplicates. Trypsin-digested samples were analysed by LC-ESI-MS/MS using nanoflow HPLC 
bioRxiv preprint doi: https://doi.org/10.1101/2020.09.29.318766; this version posted March 5, 2021. The copyright holder for this preprint

(which was not certified by peer review) is the author/funder, who has granted bioRxiv a license to display the preprint in perpetuity. It is made APEX2 proximity proteomics of B cell activation available under aCC-BY-ND 4.0 International license.

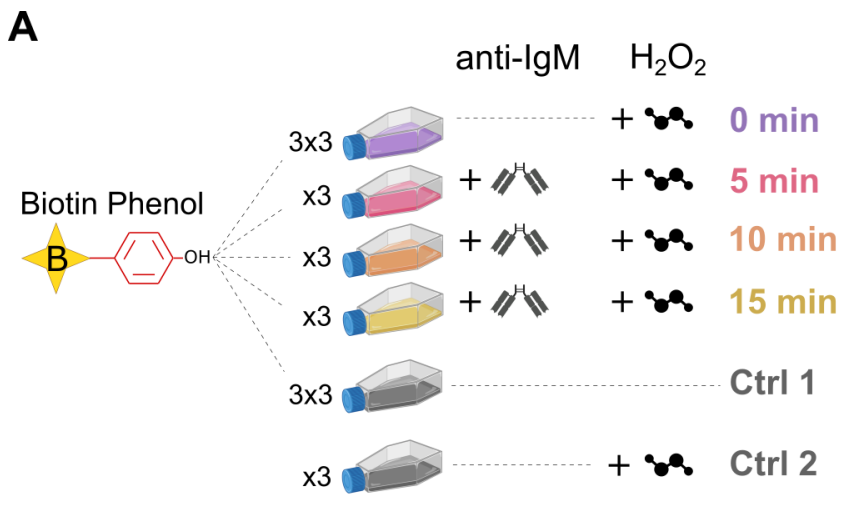

C

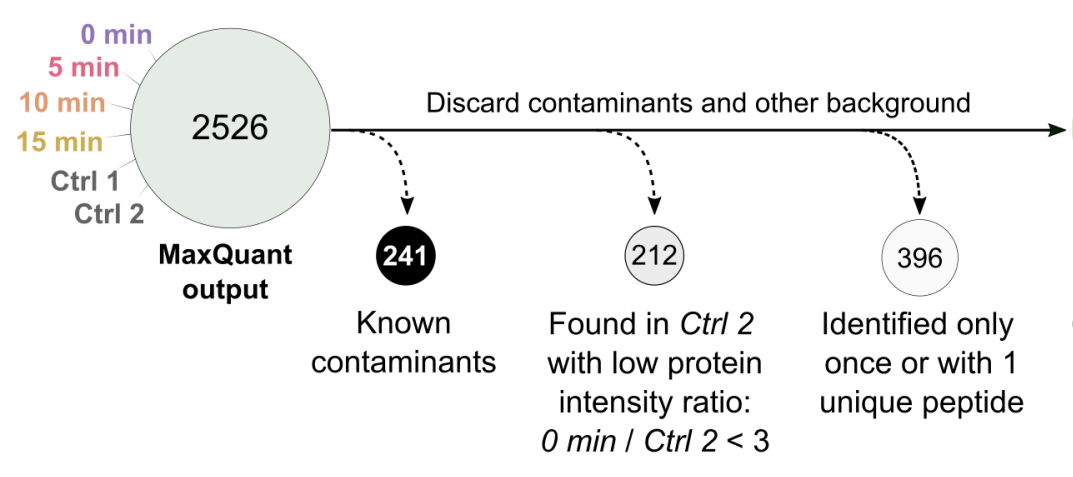

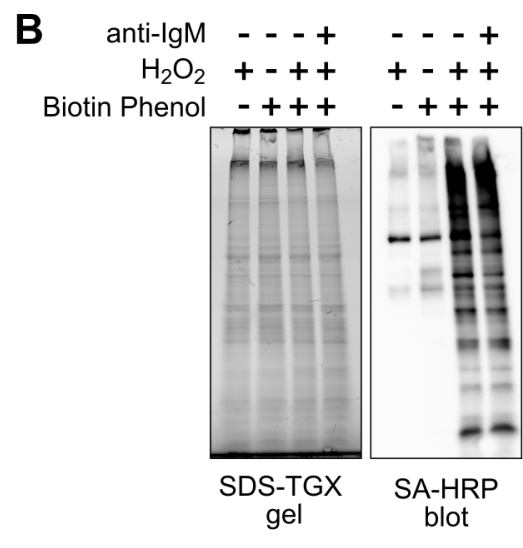

Total cell lysates

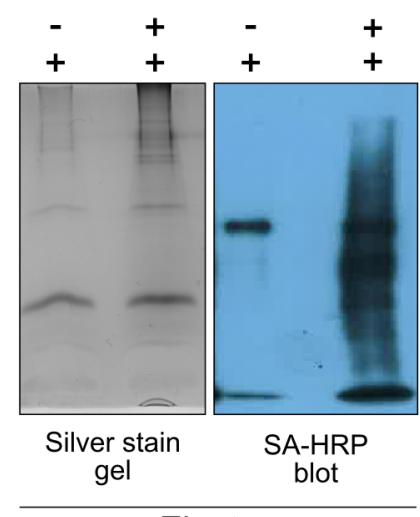

Eluates

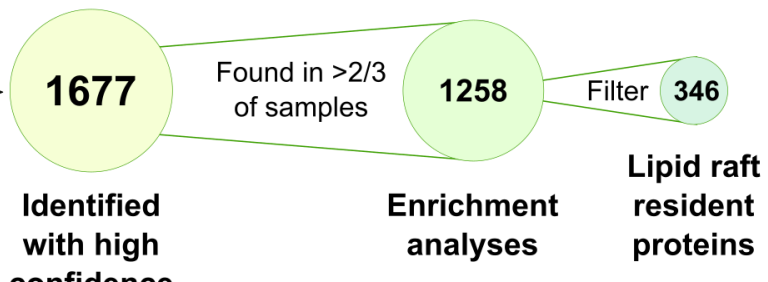

D

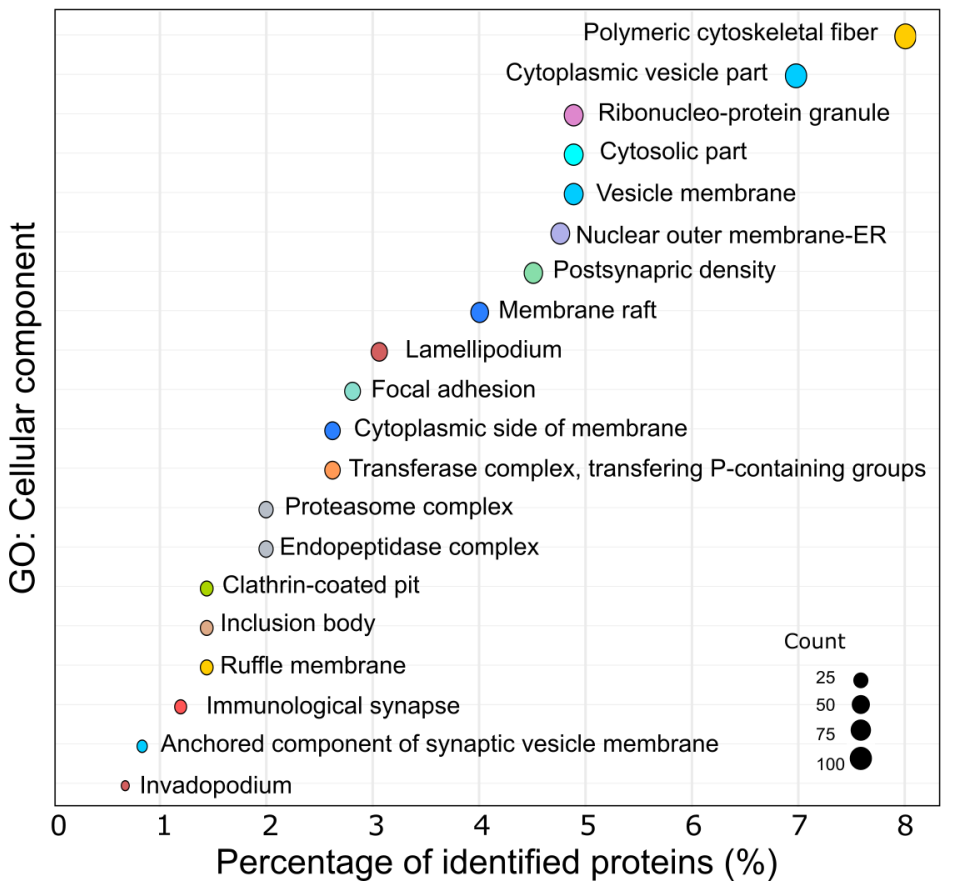

E

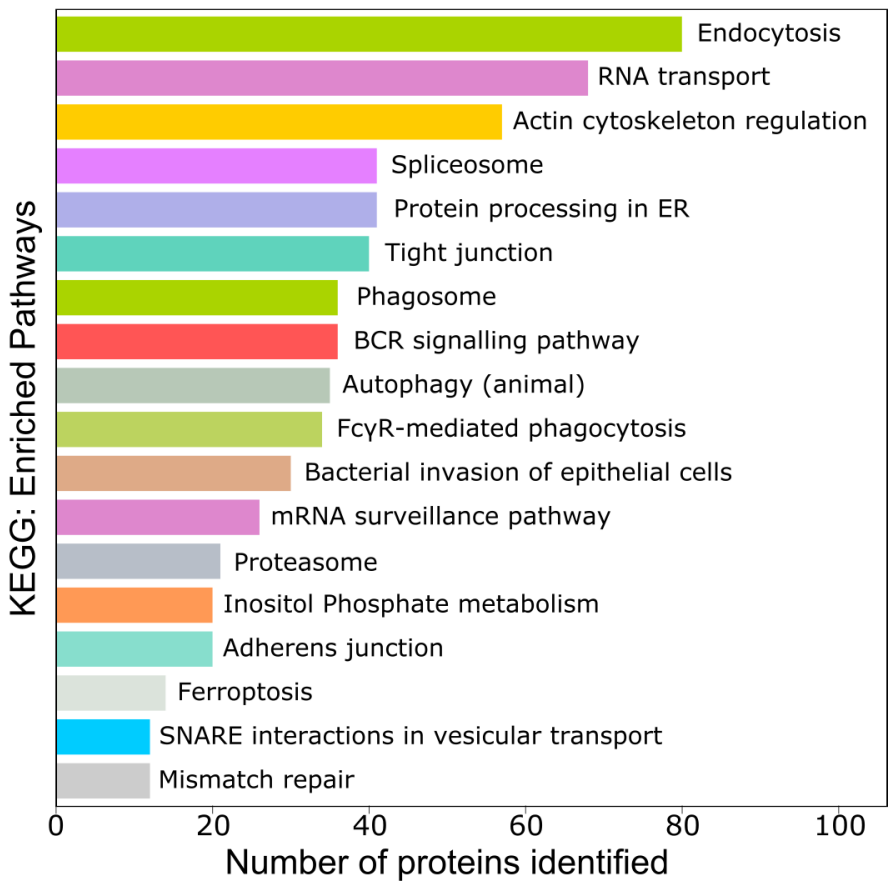

Figure 2: Experimental design and pathway analysis. A) schematic representation of the experimental samples and controls prepared and analysed by quantitative label-free MS in this study. Three different biological replicates were prepared for all conditions. B) To monitor for basal levels of biotinylation, raft-APEX2 expressing A20 D1.3 B cells were subjected to alternating conditions of anti-IgM stimulation $(10 \mu \mathrm{g} / \mathrm{ml}, 10 \mathrm{~min}), \mathrm{H}_{2} \mathrm{O}_{2}(1 \mathrm{mM}, 1 \mathrm{~min})$ or biotin-phenol $(500 \mu \mathrm{M}, 45 \mathrm{~min})$. Left: Total cells lysates were analysed with TGX Stain-Free SDS gel, and a Western blot probed with streptavidin-HRP. Right: The samples eluted from the streptavidin-coated beads were analysed with a Silver stained SDS-PAGE, and a Western blot probed with streptavidin-HRP. C) Flow chart shows the filtering steps used for the data analysis. D) A KEGG pathway enrichment analysis for the 1677 identified proteins shows cellular (Continued) 
Figure 2: (Continued) pathways enriched among the identified proteins. To remove redundancy in the identified pathway terms, terms that had $\geq 50 \%$ similarity were grouped and the one with the lowest adjusted p-value is shown. E) Classification of the 1677 identified proteins based on cellular component gene ontology (GO) terms. To remove redundancy in the GO terms, GO terms that had $\geq 50 \%$ similarity were grouped and the one with lowest adjusted p-value is shown.

system (Easy-nLC1200, Thermo Fisher Scientific) coupled to the Orbitrap Fusion Lumos mass spectrometer and peptide/protein calling was done with MaxQuant software (Cox E Mann, 2008). Differential analysis was done using NormalyzerDE (Willforss et al., 2019). After filtration of known contaminants and background, we found 1677 proteins with 2 or more unique peptides identified (Fig.2C and Suppl. File 1A). High confidence hits from all experimental conditions together are listed in the Supplementary File 1A. As expected, we detected, with very high intensity values, several proteins associated with lipid rafts and BCR signalling (Suppl. Files 2, 4A and Fig2D, E). At the same time, the large total number and variety of identified proteins illustrate the high efficacy of APEX2mediated protein biotinylation that reaches also to the cytosolic environment immediately beneath the membrane.

Lipid raft-resident proteins in B cells As a way to further validate the lipid raft localisation of our raftAPEX2 construct, we first shortlisted our data for proteins that were likely to reside at the closest vicinity to raftAPEX2. Here, we analysed the protein intensities between the experimental samples and the control samples without added $\mathrm{H}_{2} \mathrm{O}_{2}$, using a similar approach as Paek and colleagues (Paek et al., 2017). Taking into consideration the low-level basal activity of APEX2, we took an assumption that the proteins locating at the closest vicinity to the raftAPEX2 are prone for biotinylation already before extracellular addition of $\mathrm{H}_{2} \mathrm{O}_{2}$, with the aid of low-level endoge- nous $\mathrm{H}_{2} \mathrm{O}_{2}$. The same proteins are expected to be very efficiently labelled upon addition of $\mathrm{H}_{2} \mathrm{O}_{2}$ and, thus, yield high peptide intensities in the MS data. We selected proteins that were identified in control samples and showed a prominent, $\geq 1.5 \log _{2}$ fold change upon triggering of biotinylation by $\mathrm{H}_{2} \mathrm{O}_{2}$. Additionally, we filtered out proteins that responded with $\geq 1.0 \log _{2}$ fold change to BCRstimulation to selectively shortlist only those proteins that were constantly at the closest vicinity of raft-APEX2. As a result, we identified 346 proteins that we considered as B cell raft-resident proteins (Suppl. File 2). Almost 90\% of the proteins were also found in the available RaftProt databases (Mohamed et al., 2019) (Fig.3A, Suppl. Fig.S2A), providing important confidence to the preferred raft localisation of our APEX2 construct. Among the strongest raftresident proteins that showed most prominent intensity increase upon $\mathrm{H} 2 \mathrm{O} 2$ addition were, for instance, Dock8 and Hcls1, reported regulators of BCR signalling and B cell activation (Hao et al., 2004; Randall et al., 2010), as well as filamin and spectrin, scaffold proteins linking the plasma membrane and the underlying cytoskeleton (Liem, 2016; Razinia et al., 2012) (Fig.3B). An earlier study by Saeki and colleagues identified 34 proteins in the isolated detergent-resistant membrane domains from human Raji B cells (Saeki et al., 2003). Out of these 34, our approach identified 20, of which 10 proteins as raft-resident proteins (Suppl. Fig.S2A). The lack of the 10 previously proposed raft proteins could be explained by possible resis-

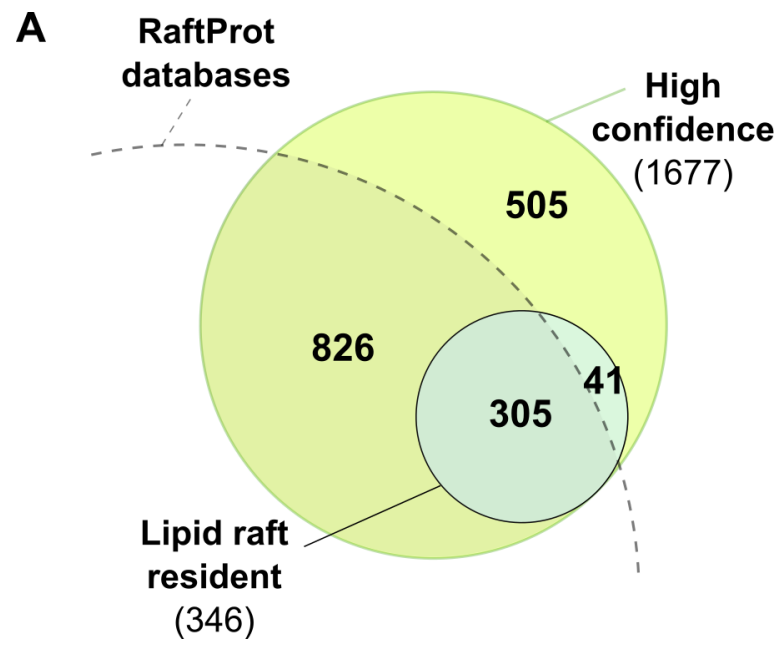

B

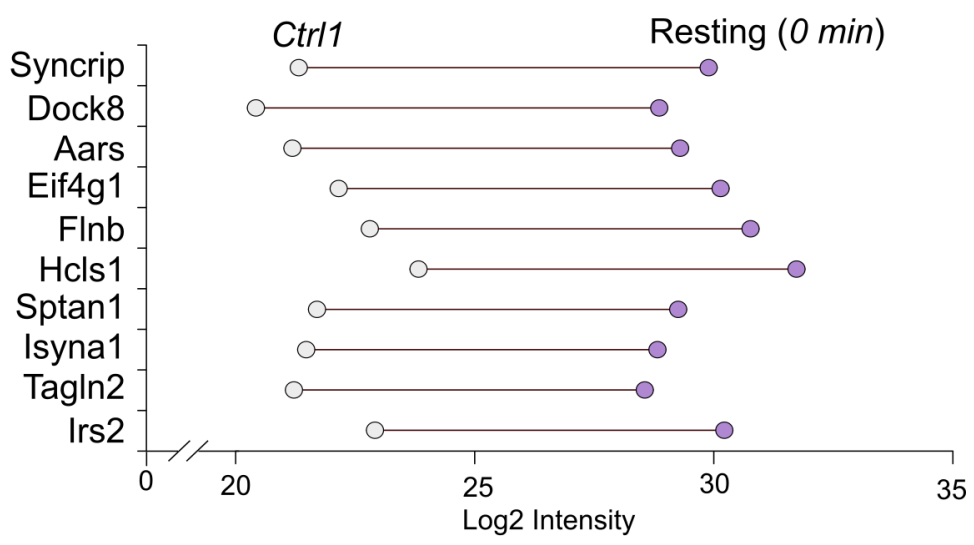

Figure 3: Lipid raft-resident proteins. A) A comparison of the lipid raft-resident proteins identified in this study and the whole dataset of 1677 proteins to the RaftProt database shows the overlap between the datasets. B) Top ten proteins that show the highest enrichment in the lipid rafts of $\mathrm{B}$ cells as reported by raft-APEX2-mediated biotinylation prior (control 1) and post addition (resting, 0 min) of $\mathrm{H}_{2} \mathrm{O}_{2}$. The difference of the protein intensities between the two conditions was used for ranking. 
A
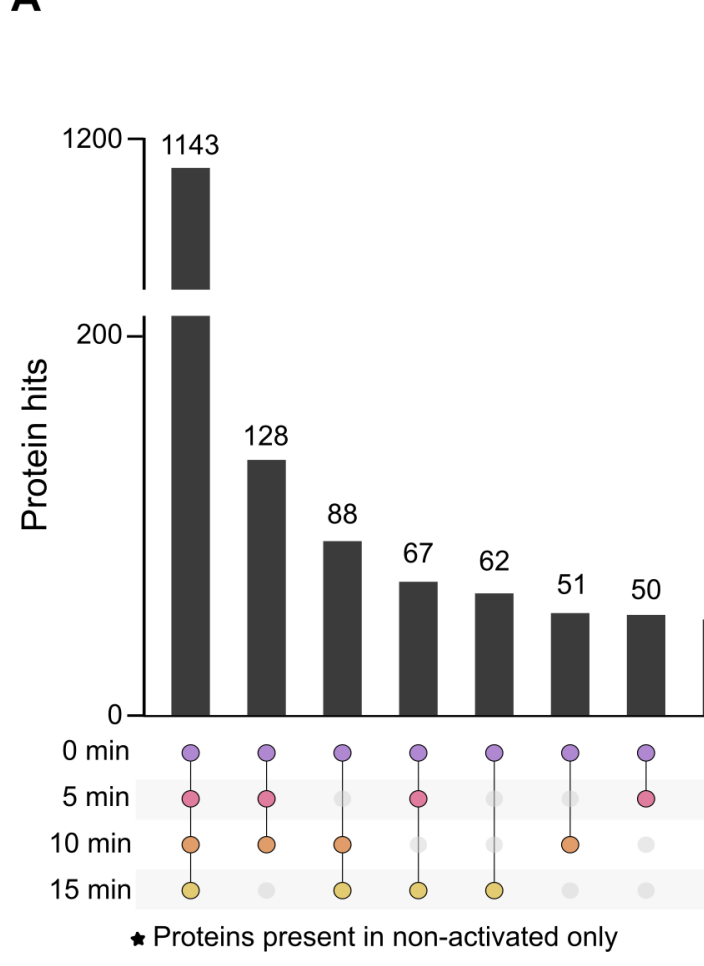

B

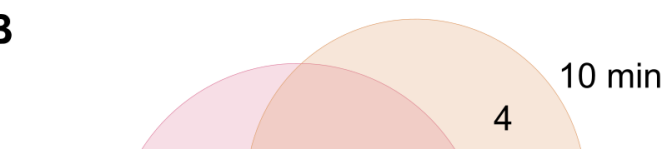

$5 \min$

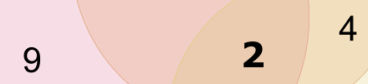

Cab39

Cdc34

4 Alad

Csrp2 Atg2b Ak2

Exosc3 Dis3 C2cd2I

Irf8 Emc3 Crnkl1

LIph Map3k15 Cux1

Sec61a1 Riox2 Gorasp2 Cep43 Ankib1

Tollip Rnf31 Icam1 Impdh1Dcun1d5 Il6st,

Ttc27 Trnt1 Ppid Tnfaip8 Hmgb2 Nt5dc1 Golga3

Xrn1 Zzef1 Septin11 Ubxn7 Ncor1 Riok2 Kif20A
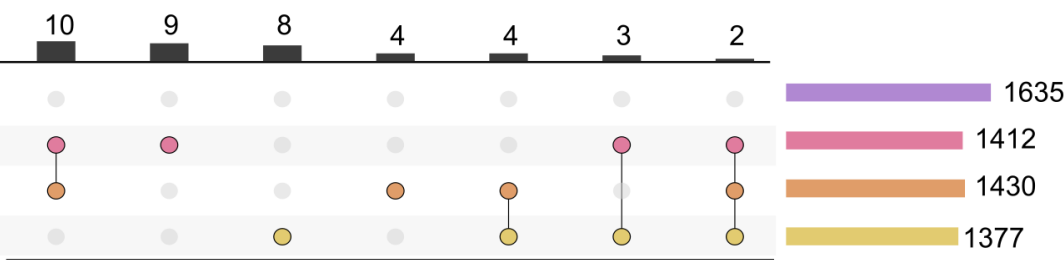

Proteins present in activated-samples only (5-15 min)

$15 \min$

Figure 4: Proteins identified in different conditions of BCR activation. A) An UpSet plot showing the numbers of proteins identified in each experimental condition. When 10 or less proteins were identified, the names of the identified proteins are shown on top of the bar. B) A Venn diagram showing intersections of proteins identified in activated samples (5, 10 and 15 min of anti-IgM stimulation).

tance for biotinylation, the differences between the in vitro biochemical fractionation and in cellulo labelling, or simply the different cell line used.

Membrane-proximal proteome. To obtain a broad view on the full set of 1677 proteins identified in our study, we used GO cellular components analysis (Ashburner et al., 2000) and KEGG pathway assignment (Kanehisa et al., 2016). We identified the highest protein counts in various cytoskeletal and membrane structures, linked to fundamental cell biological pathways such as regulation of the actin cytoskeleton and endocytosis (Fig.2D, E). Among the more specific terms, we found "Membrane rafts", "Immunological synapse" and "BCR signalling" to significantly enrich in our data, providing confidence to our approach to detect changes in the protein environment linked to BCR signalling. Out of total of 1677 high confidence hits in our data (Suppl. File S1A), a large majority, 1143 proteins, were common to all conditions. 48 proteins were specific for resting cells and 40 were specifically detected only upon BCR activation (Fig.4A, B and Suppl. File 1B, C). Only 2 proteins, Kif20 and Golga3, were found in all activation time points and not in any of the non-activated controls (Fig.4A, B and Suppl. File 1C). A major part of our dataset consisted of proteins that were found present in all or most of the conditions. The protein abundance in each sample was obtained via intensity analysis using MaxQuant software. For statistical analy- sis of the changes in protein abundance at different conditions, we first applied the criteria of the proteins needing to be present in at least 12 out of 18 experimental samples, which restricted the analysis to 1258 proteins (Fig.2C,5A, $\mathrm{B}$ and Suppl. File 3A). The missing values were then imputed using k-Neareast Neighbor $(\mathrm{kNN})$ and quantitative differential analysis was done using NormalyzerDE (Willforss et al., 2019). The majority of the proteins did not undergo significant dynamics upon BCR activation but instead showed relatively stable abundance throughout different conditions. 213 proteins showed significant dynamics with $\log _{2}$ fold change $\geq 1.5$ or $\leq-1.5$ upon cell activation (Fig.5B, Suppl. FileS3B). Distinct sets of proteins were found to be enriched, or diminished, upon different time points. While 75,53 and 55 proteins were significantly altered at 5, 10 and 15 min time points, respectively, only 7 proteins were found significantly altered at all the studied time points (Fig.5A, B). Interestingly, of those 7 proteins, two, namely Shq1 and PolR2c, changed from being significantly downmodulated to significantly enriched or vice versa. These findings suggest that while most of the proteins do not change their localisation dramatically, there is a minor fraction of proteins that clearly respond by translocations. Interestingly, our dataset also contained a significant fraction of proteins linked to cellular machineries that are generally not associated with the vicinity of the plasma membrane, such as ribosomes, regulation of 
translation and RNA transport (Fig.2E). Arguing against identification of these proteins as potential background resulting from low-intensity biotinylation or unspecific binding to the streptavidin beads, several such proteins were identified amongst the lipid raft-resident proteins, i.e. with very intimate colocalisation with raft-APEX2 (Suppl. File 2). Also, two earlier independent studies have reported ribosomal and nuclear proteins undergoing S-acylation modification targeting them to the lipid raft domains (Martin \& Cravatt, 2009; Yang et al., 2010). The prominent lipid raft localisation of ribosomes, could also contribute to the abundance of proteins linked to endoplasmic reticulum, RNA transport and ribonuclear protein granules. Interestingly, proteins associated with transcriptional regulation, as defined by belonging to the functional category "transcription" at DAVID knowledgebase (Huang et al., 2009b,a), constituted about $10 \%$ of the detected proteome. We found, for instance, that NF- $x \mathrm{~B}$ proteins, c-Rel, RelA, NF- $\chi \mathrm{B} 2$ and regulatory $\mathrm{I} \chi \mathrm{B} \alpha$ are identified in the vicinity of the raft domains of non-activated $B$ cells and show dynamic behaviour upon BCR activation (Suppl. Fig.S3A). FoxO1 transcription factor, whose translocation out of the nucleus is mediated by PI3K-Akt signalling (Brunet et al., 1999), associated with raft-APEX2 at $15 \mathrm{~min}$ after activation. The transcription factors particularly important for B cell development and differentiation, IRF5 and IRF4, were detected at the raft proximity in all conditions. This could be explained by the association of IRFs with membrane-proximal TLR adapter protein MyD88 and Src kinases, including Lyn (Negishi et al., 2005; Ban et al., 2016). The possible unexpected relationships, suggested by our data, between BCR signalling, plasma membrane, and proteins playing a role in translational regulation, RNA transport and nuclear transport, are interesting topics for future studies.

The dynamics of proteins linked to BCR signalling As expected, Ighm, and IgK-V, the heavy and light chain components of the transgenic IgM BCR specifically activated in our setup, showed greatly increased intensity in activated samples (Suppl. File 3A, B; Fig.5A, C). This finding importantly agrees with the translocation of IgM to the lipid raft domains, as expected. In contrast, Ighg, the endogenous IgG2a BCR, remained largely unchanged upon receptor activation. This notion proposes that the mechanisms driving activated BCR to the lipid raft domains have specificity to antigen engaged receptors and do not carry notable bystander effect, at least in interisotype manner, that would change the localisation of the unligated BCRs. However, in comparison to IgM, IgG2a was detected at higher levels already in resting cells, suggesting for stronger tendency to localise to lipid rafts prior to activation (Suppl. File 2). Interestingly, despite of substantial enrichment of IgM heavy chain and kappa light chain to the lipid rafts upon activation, we saw decrease in the abundance of $\operatorname{Ig} \alpha$ and $\operatorname{Ig} \beta$, proteins essential for both signal transmission and the stability and membrane transport of the BCR (Fig.5C). This finding would indicate that the local ratio of $\operatorname{Ig} \alpha / \beta$ and the BCR heavy chain is not fixed but can be tuned depending on the membrane location and/or the activation state. Our data suggests that upon cross-linking, perhaps facilitated by tighter molecular organisation, IgM molecules could more efficiently share their $\operatorname{Ig} \alpha / \beta$ sheath molecules increasing the $\operatorname{IgM}: \operatorname{Ig} \alpha / \beta$ ratio. When analysing the known components of the BCR signalling pathway, the results were somewhat unexpected. We did not identify prominent $\mathrm{BCR}$ regulator proteins among the proteins exclusively found either in resting cells or activated cells (Fig.4A) promoting rather incremental changes in the signalling protein localisation than dramatic translocations induced by antigen engagement. Various components of the BCR signalling pathway did either not show significant dynamics, or they rather showed diminution while the IgM was translocating to the lipid rafts (Fig5C). This is consistent with proximal receptor signalling cascades being typically heavily dependent on protein modifications such as phosphorylation, which are not necessarily reflected as changes in total protein localisation. Among the identified tyrosine kinases involved in early BCR signalling were Lyn, Fyn, Blk, and Btk (Suppl. File 1A). Lyn is often considered as one of the main kinases triggering $B C R$ signalling, due to its early requirement to phosphorylate $\operatorname{Ig} \alpha / \beta$ ITAM motifs, and it also preferentially locates to the lipid rafts (Xu et al., 2005). Accordingly, we found Lyn in the rafts in all conditions, however, it was significantly diminished upon BCR activation. Total internal reflection microscopy (TIRFM) of B cells activated on bilayers indicated that while Lyn does colocalize with clustered BCR, the confinement to the clusters is not very clear and, interestingly, the closest vicinity to the BCR, measured by fluorescence resonance energy transfer (FRET), is seen within the first $200 \mathrm{~s}$ of BCR activation, after which the interaction diminishes (Sohn et al., 2008). On the other hand, BCR signalling was reported to have no effect on the enrichment of Lyn in isolated rafts (Gupta et al., 2006). The existing ambiguousness over the mechanistic details of Lyn, further complicated by the dual role of the kinase as both negative and positive regulator of BCR signalling ( $X u$ et al., 2005).The triggering of $B C R$ signalling cascade is shared with Fyn, another Src-family protein tyrosine kinase (Xu et al., 2005). In our data, Fyn shows higher abundance across the conditions and seems to be largely located at the lipid raft-like regions. Another Src-family kinase identified in our data was Yes. Although not commonly linked to BCR signalling, we detected a significant enrichment of Yes at the lipid rafts at $5 \mathrm{~min}$ activation. From the other 
bioRxiv preprint doi: https://doi.org/10.1101/2020.09.29.318766; this version posted March 5, 2021. The copyright holder for this preprint

(which was not certified by peer review) is the author/funder, who has granted bioRxiv a license to display the preprint in perpetuity. It is made APEX2 proximity proteomics of B cell activation available under aCC-BY-ND 4.0 International license.
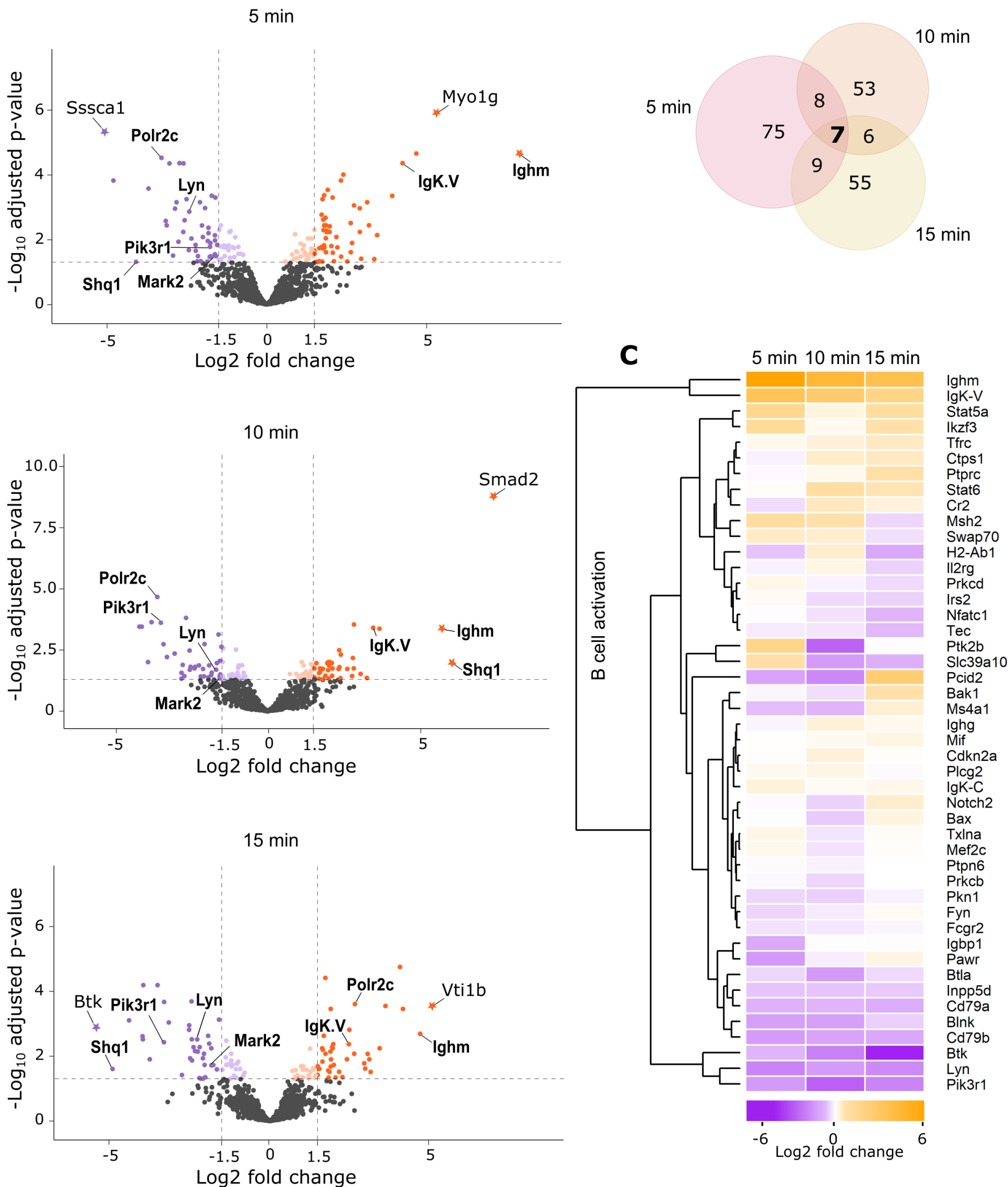

Figure 5: Enrichment analysis. A) Volcano plots illustrate the detected protein intensity dynamics upon anti-BCR activation at 5, 10 and $15 \mathrm{~min}$. The data is based on the differential enrichment analysis of 1258 identified proteins (see Fig.2C). The proteins showing statistically significant (adjusted p-value $\leq 0.05$ ) enrichment in non-activated conditions are shown in violet and in activating (Continued) 
bioRxiv preprint doi: https://doi.org/10.1101/2020.09.29.318766; this version posted March 5, 2021. The copyright holder for this preprint

(which was not certified by peer review) is the author/funder, who has granted bioRxiv a license to display the preprint in perpetuity. It is made APEX2 proximity proteomics of B cell activation available under aCC-BY-ND 4.0 International license.

Figure 5: (Continued) conditions in orange color. The proteins with a $\log _{2}$ fold change $\geq 1.5$ are further denoted with stronger color tone.

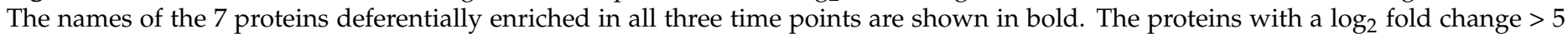
are denoted with a star symbol. B) A Venn diagram showing the numbers of significantly enriched proteins with log ${ }_{2}$ fold change $\geq$ 1.5 at any time points and their intersections. In total, 213 proteins. C) A heatmap of proteins classified to GO term "B cell activation" showing the changes in the protein intensity at different time points of BCR activation.

components of the BCR signalling pathway, for example, the activatory co-receptor CD19 was constantly found in high abundance in all samples and classified as a lipid raft-resident protein (Suppl. File 2) (Fig.5C). This could suggest that the reported enrichment of the CD19 in the BCR signalling microclusters (Depoil et al., 2008; Mattila et al., 2013) would reflect gathering of the raft domains already containing CD19. Two other transmembrane proteins linked to BCR activation predominantly as negative regulators, Siglec CD22 and FcgR2, were also identified in the data. While CD22 showed enrichment to the lipid rafts at 5 min of activation FcgR2 was defined as lipid raft-resident protein. Btk, an important regulator of BCR downstream signalling, also showed increasing strong negative fold-change upon activation, indicating exclusion from the forming BCR clusters in these settings. Btk is known to be recruited to the plasma membrane by $\mathrm{PI}_{(3,4,5)} \mathrm{P}_{3}$ phosphoinositide, a signalling lipid critical for B cell activation (Saito et al., 2001). Consistently, we detected a strong diminution of the regulatory subunit of PI3-kinase, Pik3r1, from the lipid rafts upon cell activation. These notions would suggest early separation of the $\mathrm{IP}_{3}$-signalling from the immediate vicinity of the BCR. Also, B cell linker (BLNK), a binding partner of Btk and various other BCR signalling proteins was significantly downregulated at the rafts upon BCR activation, although it showed substantial abundance throughout the conditions. Phospholipase- $\gamma_{2}\left(\mathrm{PLC} \gamma_{2}\right)$, that forms the other branch of lipid signalling downstream of BCR, was found constitutively present as a lipid raft-resident protein (Suppl. File 2). In summary, intriguingly, we found $\mathrm{BCR}$ signalling proteins mostly either non-dynamically raft-resident, or decreasing from the raft regions upon activation.

Vesicle trafficking proteins Golga3 and Vti1b are novel proteins linked to early BCR signalling In addition to signalling proteins, we detected substantial dynamics of various proteins linked to the steps immediately subsequent to BCR activation, such as cytoskeleton remodelling, endocytosis and membrane traffic, all essential for internalisation of BCR-antigen complex and further processing for antigen peptide presentation. Our data illuminates employment of different regulators driving these processes, highlighting for example, existence of various components of the clathrin-mediated endocytosis (Suppl. File 4, Suppl. Fig.S3B). Several of them, such as Cltc, Hip1R and Eps15, were detected as lipid raft resident proteins (Suppl. File 2) or they got differentially enriched during BCR activation (Suppl. File 3), such as AP2 complex subunits alpha and beta. Our attention was drawn to various proteins linked to intracellular membrane traffic that showed specific recruitment towards the lipid rafts upon BCR activation. For instance, both of the proteins identified purely in activatory conditions, Golgin subfamily A member 3 (Golga3) and kinesin Kif20a (Fig.4), are associated with endomembrane system. Similarly, one of the strongest intensity enrichments in our data was detected for a SNARE protein Vtilb (Fig.5). As none of these proteins have previously been associated with BCR signalling, we sought to verify their dynamics using microscopy. Due to the lack of suitable immunofluorescence antibodies against mouse or human Kif20a, we focused on Golga3 and Vti1b. In the immunofluorescence studies we used Raji human B cell line, facilitated by the better availability of human specific antibodies but, at the same time, this served to test our findings in an unrelated B cell line. Our Raji D1.3 cell line stably expressed the same D1.3 transgenic mouse IgM BCR as the A20 D1.3 mouse cell line used in the proximity proteomic study. Golga3, also known as Golgin-160, is a peripheral membrane protein, that has been shown to localise to the Golgi apparatus but also throughout the cytosol at least in HEK293 cells and primary neurons (Dumin et al., 2006). Golga3 is a poorly understood multifunctional protein linked to regulation of membrane transport of selected plasma membrane proteins (Hicks et al., 2006; Hicks \& Machamer, 2005; Williams et al., 2006), ubiquitination (Dumin et al., 2006) apoptosis (Maag et al., 2005), and interestingly, also to dynein function (Yadav et al., 2012). In Raji B cells, we found Golga3 widely distributed in the cells in a vesicular fashion. Upon BCR activation with $\mathrm{F}\left(\mathrm{ab}^{\prime}\right)_{2}$ anti-IgM, the distribution of Golga3 vesicles indeed altered and the vesicle pool at the cell membrane became more prominent. Utilising cell volume segmentation based on microtubule staining (Suppl. Fig.S4A), we analysed the Golga3 vesicles selectively at the vicinity of the plasma membrane before and after BCR activation. We found that the Golga3 vesicles become significantly larger and brighter in the activated cells as compared to the non-activated counterparts (Fig.6A, B; Suppl. Fig.S4B). Also, the shape of the vesicles became more elongated and the vesicles showed notable, yet partial, colocalisation with internalised surrogate antigen. The colocalisation analysis at the cell periphery by Pearson's correlation coefficient, measuring overall corre- 

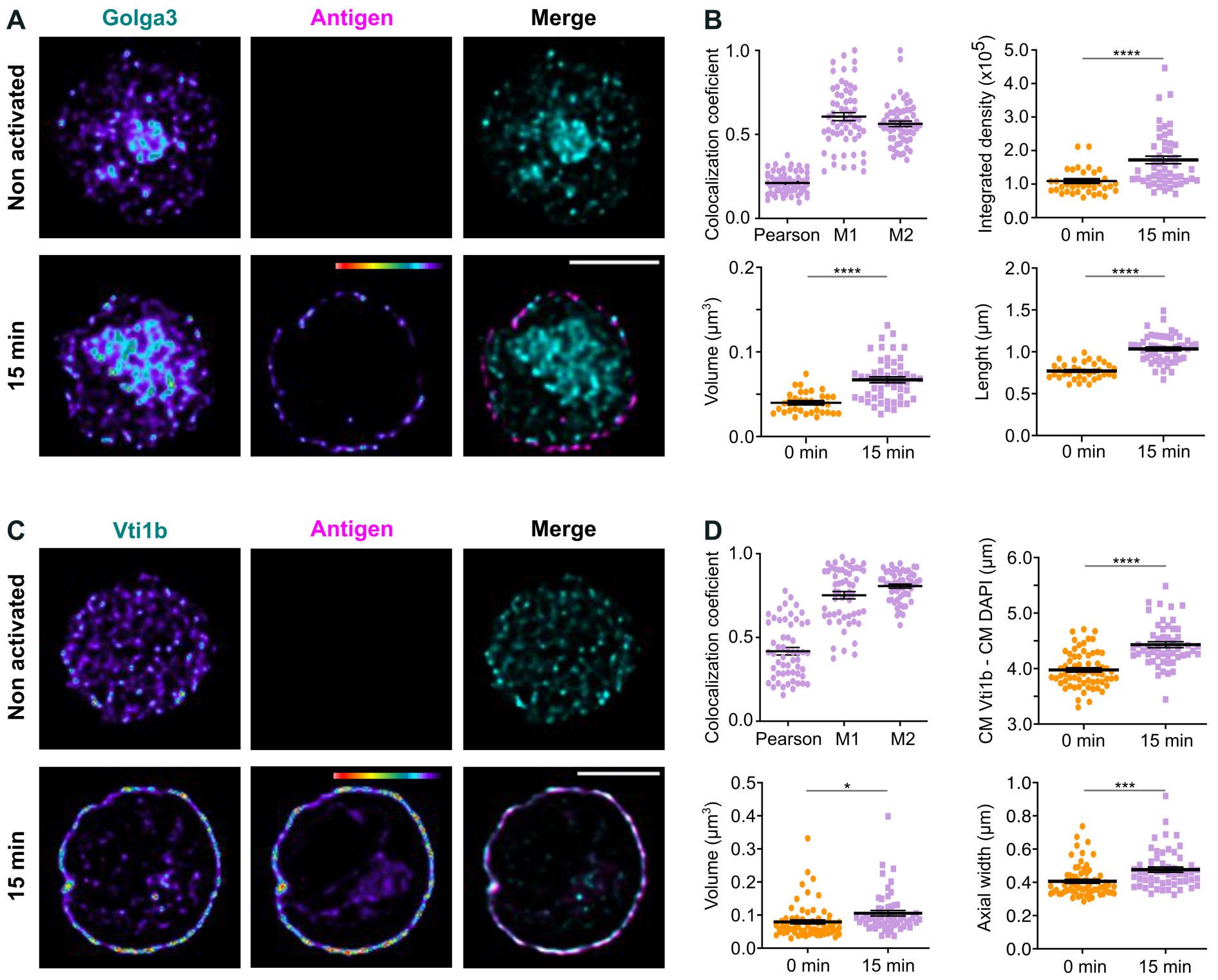

Figure 6: Translocation of Golga3 and VTI1b to the cell periphery upon BCR activation and colocalisation with antigen. A) Human Raji D1.3 B cells were let to adhere on CellTak-coated microscopy coverslips, activated (lower panel) or not (upper panel) with $10 \mu \mathrm{gg} / \mathrm{ml}$ Alexa Fluor ${ }^{\circledR}$-labelled $\mathrm{F}\left(\mathrm{ab}^{\prime}\right)_{2}$ fragments of anti-IgM antibodies (antigen, pseudocolor in single channel image and magenta in merge) for $15 \mathrm{~min}$, fixed and permeabilised and subjected to immunofluorescence analysis with anti-Golga3 (cyan) antibodies. Cells were imaged with spinning disc confocal microscopy. B) The colocalisation of antigen and Golga3 as well as the Golga3 vesicles were analysed from the cell periphery (see Suppl. Fig.S4A) from deconvoluted images. The levels of colocalisation were measured with Pearson's correlation co-efficiency (0.21) and Manders' overlap coefficiency (M1: 0.61, M2: 0.56). The intensity, volume and length of the Golga3 vesicles are shown. C) Raji D1.3 B cells were prepared as in A), but activated (lower panel) or not (upper panel) with $5 \mu \mathrm{g} / \mathrm{ml}$ hen egg lysozyme (HEL; antigen, pseudocolor in single channel image and magenta in merge) for 15 min and subjected to immunofluorescence analysis with anti-Vti1b (cyan) antibodies. Cells were imaged as in A). D) The colocalisation of antigen and Vti1b as well as the Vti1b vesicles were analysed from deconvoluted images. The levels of colocalisation were measured with Pearson's correlation co-efficiency (0.42) and Mander's overlap co-efficiency (M1: 0.75, M2: 0.81). The distance from the centre of mass (CM) of Vti1b signal to nucleus' CM (Y-axis starts at the approximate distance of the nuclear envelope from the nucleus CM), as well as the volume and length of the Vtilb vesicles is presented. Each dot represents a measure from an individual cell and results are shown as mean \pm SEM of all the cells ( $\geq 35$ cells for Golga3 and $>50$ cells for Vti1b) from $n=3$ independent experiments. Single confocal planes from deconvoluted images of representative cells are shown. Scale bar $5 \mu \mathrm{m}$. Huygens software was used for image analysis. ${ }^{* *}: \mathrm{p}<0.05 ;{ }^{* * *}: \mathrm{p}<0.001{ }^{* * * *}: \mathrm{p}<0.0001$ 
bioRxiv preprint doi: https://doi.org/10.1101/2020.09.29.318766; this version posted March 5, 2021. The copyright holder for this preprint

(which was not certified by peer review) is the author/funder, who has granted bioRxiv a license to display the preprint in perpetuity. It is made APEX2 proximity proteomics of B cell activation available under aCC-BY-ND 4.0 International license.

lation for the two signals, suggested very weak positive correlation with coefficient of 0.21 . However, Manders' overlap coefficient showed marked colocalisation of both Golga3 signal in antigen clusters (M1: 0.61), and antigen signal in Golga3 vesicles (M2: 0.56). In addition, we also investigated the protein hits showing the most dramatic enrichment response towards the lipid rafts upon BCR signalling (Fig.5A). While our dataset contained several SNARE family proteins, such as syntaxins, responsible for different membrane fusion events, most of them did not show significant dynamics upon cell activation. However, a Q-SNARE Vti1b (vesicle transport through interaction with t-SNAREs homolog 1B), showed a very strong $\log _{2}$ fold-change of 5 , being the protein most enriched at 15 min. We studied Vtilb localisation in B cells via immunofluorescence analysis first in resting cells and found it to localise throughout the cytosol in vesicular manner, in good agreement with previously published data where Vti1b has been indicated in various intracellular vesicles (Kreykenbohm et al., 2002). Importantly, we detected a dramatic change in the protein localisation upon BCR activation. Vast majority of the Vtilb signal shifted to the immediate vicinity of the plasma membrane and showed very strong colocalisation both with the surrogate antigen antiIgM and with HEL, the native antigen for the D1.3 BCR expressed in the cells (Fig.6C; Suppl. Fig.S5). The colocalisation analysis confirmed a highly significant colocalisation by both Pearson's correlation coefficient of 0.42 as well as Manders' overlap coefficients of 0.75 , for Vtilb signal in antigen clusters, and 0.81 , for antigen in Vti1 vesicles. We also quantitatively analysed the Vti1b vesicles from the whole cell volumes and detected a clear and significant shift in the centre of mass positions demonstrating translocation towards cell periphery (Fig.6D). Also, the volume and the area of the vesicles increased significantly (Fig.6D; Suppl. Fig.S5C). Notably, the striking overlap of Vti1b and antigen was diminished in the vesicles farther from the plasma membrane, indicating that Vtilb is specifically recruited to the vesicles close to the plasma membrane at the time of internalisation and shortly after that (Suppl. Fig.S5B). Considering the known functions of SNAREs in vesicle fusion, this could indicate a role for Vti1b in the early vesicle trafficking of internalised antigen. Together, the immunofluorescence studies well supported our proteomics data on identifying Golga3 and Vti1b as novel proteins translocating to the proximity of the BCR upon antigen activation.

\section{Discussion}

To better understand BCR signalling and the immediate, multibranched cellular responses it triggers, development of improved large-scale approaches with sufficient spatiotemporal resolution are critical. Here, we pioneer
APEX2-mediated proximity biotinylation proteomics approach, to track at large scale, protein dynamics at the plasma membrane lipid raft domains where BCR translocates upon activation. As APEX2 efficiently biotinylates its vicinity in the range of $20 \mathrm{~nm}$ in the time scale of $1 \mathrm{~min}$, it poses significant power to report on protein abundancies at large scale in a time-resolved manner. By identifying and quantitatively analysing over 1600 proteins, we draw a landscape of proteins at or very close to the plasma membrane in B cells and report their dynamics during BCR activation. Our data proposes various new protein players responding to the BCR signalling, out of which we were able to validate two vesicle traffic regulators, Golga3 and Vti1b. With its high efficiency, APEX2-based proximity proteomics provides a sought-after opportunity for an ensemble view to the various cellular machineries triggered upon BCR activation. After facing challenges in fusing APEX2 to the signalling subdomains of the BCR, we took advantage of the well-described translocation of the receptor to the lipid rafts upon activation. As compared to direct targeting of APEX2 to the BCR or other functional proteins, we postulated that targeting by a lipid raft directing lipidation sequence implied a minimised risk of interference with the signalling cascades while still reporting about BCR vicinity with good accuracy. We successfully verified the preference of our construct to the plasma membrane and the vicinity of IgM by microscopy (Fig.1) and, more specifically, to the lipid raft domains by detergent treatment followed by flow cytometry analysis (Suppl. Fig.S1A, B). Although a fraction of the probe might remain also in the non-raft regions, strong preference to lipid rafts was clear and also supported by our shortlisting of the most efficiently and constitutively biotinylated proteins, out of which $90 \%$ were found in the RaftProt database (Mohamed et al., 2019) (Suppl. File 2). We also saw a drastic enrichment in IgM BCR in activatory conditions (Fig.5) further proving the correct targeting of the APEX2 and the validity of this approach to report on BCR-proximal proteome. Of the 1677 proteins identified, a vast majority were detected, at least to some level, both in resting and activatory conditions. This can be a consequence of the known heterogeneity of the raft domains (Sezgin et al., 2017) or simply from the high sensitivity of APEX2-mediated biotinylation leading to detection of also those proteins that are present at low levels. 88 proteins were selectively identified either in resting or activated cells (Fig.4). Additionally, the quantitative analysis revealed 213 proteins with a condition-specific enrichment profile (Fig.5B). The relatively small proportion of differentially behaving proteins is consistent with only a few changes reported to occur in the isolated lipid rafts upon BCR signalling (Gupta et al., 2006). Unfortunately, the study of Gupta and colleagues only reports 
bioRxiv preprint doi: https://doi.org/10.1101/2020.09.29.318766; this version posted March 5, 2021. The copyright holder for this preprint

(which was not certified by peer review) is the author/funder, who has granted bioRxiv a license to display the preprint in perpetuity. It is made APEX2 proximity proteomics of B cell activation available under aCC-BY-ND 4.0 International license.

a selected and limited set of 39 proteins in rafts making thorough comparisons between the data impossible. The highly dynamic nature of the BCR signalling response was clear in the data such that several changes occurring at 5 minutes after activation, for instance, were seen reset by 10 or 15 min (Fig.4). Interestingly, in general, we found slightly more proteins diminished than enriched at lipid rafts upon signalling. This is in agreement with the fusion and stabilisation of lipid rafts to promote signalling microclusters concomitant with coming together of smaller nanoclusters (Gupta \& DeFranco, 2003; Mattila et al., 2013, 2016; Stone et al., 2017), which could reduce the detection of proteins locating preferentially at the borders or surroundings of the rafts. The presence of 48 proteins exclusively in non-activated samples (Fig.4A and Suppl. File 1B) shows BCR-induced exclusion of quite a substantial set of proteins, perhaps partially reflecting the reorganisation of the plasma membrane but also suggesting interesting new players orchestrating the signalling cascades. Also, while the abundance of the IgM BCR itself drastically and clearly increased upon activation, the known components of the BCR signalling pathway showed variable responses (Fig.5C). For example, we noticed an interesting reduction in the abundance of Lyn, Btk, and the $\operatorname{Ig} \alpha / \beta$ signalling sheath of the $B C R$, which could indicate that some parts of the signalling pathways separate from the lipid rafts, which on the other hand, become platforms for BCR endocytosis. The reduction of $\operatorname{Ig} \alpha / \beta$ upon BCR triggering was, however, not reported in the isolated lipid rafts and also no changes in the levels of raft-bound Lyn were declared (Gupta et al., 2006). However, Gupta et al report similar reduction in the levels of Ezrin and similar increase in the levels of Myh9 as we observed in our setup. As expected, we found several BCR signalling proteins readily located in the lipid rafts, as suggested by the robust detection of many of them already in the steady state (Suppl. File 1) as well as the raft-resident, non-BCRresponsive localisation of some of them, such as $P L C \gamma_{2}$ and CD19 (Suppl. File 2). Thus, the strong translocation of the engaged BCR to the rafts could promote signalling in an energy efficient manner, as it reduces the need of various other concerted protein translocations. A crucial role in BCR signalling is played by protein phosphorylation cascades that have been studied in good detail. This level of regulation was not analysed in this study. Rapidly adjustable post-transcriptional modifications are, however, well-suited drivers for fast signalling events and might not always go fully hand-in-hand with the slower protein translocations. It is also important to note that while a wealth of our knowledge about BCR signalling comes from studies using soluble antigen, the specific details about signalling protein recruitment are largely derived from microscopy studies using surface-bound anti- gens, and might differ between different forms of antigenic stimuli (Depoil et al., 2008; Harwood \& Batista, 2010; Kuokkanen et al., 2015; Mattila et al., 2016). In future studies, it will be very interesting to apply the APEX2 proximity proteomics to the $\mathrm{B}$ cell activation by surface-bound antigens. Of note, some of the expected proteins linked to BCR signalling, such as Syk, were not identified in the data. Such lack of detection can be caused by several reasons. For example, some proteins are inherently challenging to be detected by MS, or APEX2-mediated biotinylation might be inefficient due to steric obstruction by other proteins, or there might be a lack of suitable amino acid moieties on the protein surface. On the other hand, somewhat unexpectedly, we detected various nuclear proteins, ribosomal proteins and transcriptional proteins. Arguing against unspecific background, many of them showed marked intensity and qualified as B cell lipid raft-resident proteins, or showed significant enrichment upon BCR cross-linking. The detection of many of these proteins could indeed be explained by direct targeting to the lipid raft membrane domains. Two independent studies, in T cell hybridoma and prostate cancer cells, suggested a set of ribosomal and nuclear proteins to undergo S-acylation and discovered their targeting to the lipid rafts (Martin \& Cravatt, 2009; Yang et al., 2010). Also, increased tyrosine-phosphorylation of eIF3 complex proteins has been observed upon antigen stimulation of B cells (Matsumoto et al., 2009), further advocating that some translational regulators could be early targets of BCR signalling. Membrane localisation may serve a regulatory role for these transcriptional and translational regulators and $\mathrm{BCR}$ activation with its gathering to the lipid raft domains could, either directly or indirectly, induce the release of this reserve. As we know from the previous studies, large part of the antigen-BCR complexes are internalised soon after BCR activation and they rapidly target to peripheral, early antigen processing compartments, eMIICs, locating immediately beneath the plasma membrane (Hernández-Pérez et al., 2020). Accordingly, many of the proteins that we identified with marked dynamic response to BCR signalling were linked to different branches of intracellular vesicle trafficking or cytoskeletal reorganisation. As potential novel regulators of $B$ cell activation, we chose to validate the observed BCR-induced translocation of Vtilb and Golga3 by immunofluorescence studies. We indeed detected recruitment of Golga3 and VTI1b to the vicinity of the plasma membrane and the BCR (Fig.6). Golga3 showed partial overlap with antigen and a significant change in its vesicular appearance in the periphery of the cells upon BCR activation. In the literature, Golga3 has been shown to recruit cytoplasmic dynein, a minus-end microtubule motor protein, to the Golgi apparatus, and to be responsible for 
the positioning of the Golgi to the vicinity of the centrosome (Yadav et al., 2012). Thus, it is tempting to speculate that Golga3 could be involved in the centripetal movement of internalised antigen vesicles in B cells. For Vti1b, our immunofluorescence analysis revealed an extremely strong translocation to the plasma membrane upon BCR activation, as well as a striking colocalisation with antigen (Fig.6). Vti1b belongs to the SNARE family of proteins responsible for specific membrane fusion events and has been mainly linked to late endosomal vesicle traffic ( $\mathrm{An}$ tonin et al., 2000) and macroautophagosomal maturation (Chou et al., 2020). Interestingly, in immune cells, Vti1b has been reported to play specialised roles. In cytotoxic $T$ cells it has been reported essential for lytic granule exocytosis (Dressel et al., 2010). Also, it was recently suggested that Vti1b interacts with the invariant chain of MHC and directs the specific membrane fusion events in the early endosomal pathway that allow efficient antigen processing and MHC antigen loading (Margiotta et al., 2021). As our previous work demonstrated that MHCII and the internalised antigen/BCR complex colocalise immediately after internalisation (Hernández-Pérez et al., 2020), it could be postulated that VTI1b would serve as a link to direct antigen/BCR complexes and MHCII to the newly formed eMIICs and to the correct endosomal path for antigen processing and peptide antigen presentation on MHCII in B cells. Altogether, our results draw an important picture of the overall proteome at the B cell plasma membrane and provide both a comprehensive view and unprecedented information on the protein dynamics responding to $\mathrm{BCR}$ signalling. Our work provides a pioneering example of the application of proximity biotinylation to study antigen receptor signalling. At the same time, as lipid rafts have been identified as hotspots for various membrane receptors and signal transduction machineries (Mollinedo $\mathcal{E}$ Gajate, 2020; Varshney et al., 2016) our approach can serve as an easily adaptable platform also for studies of other signalling systems.

\section{Materials and Methods}

Design and cloning of raft-APEX2. pcDNA3-mitoAPEX (Rhee et al, 2013) was a kind gift from Alice Ting (Addgene plasmid \#42607) and it was used as a template to create and PCR amplify V5 (GKPIPNPLLGLDST) epitope tagged APEX2 cDNA. mCherry with N-terminal seven amino acid sequence (MGCVCSS) that encodes the acylation sequence and APEX2 were then cloned into pcDNA $^{\mathrm{TM}} 4 / \mathrm{TO}$ plasmid with zeocin selection (Invitrogen V1020-20).

Cells. The mouse A20 and human Raji B cell lines stably expressing a hen egg lysozyme (HEL)-specific IgM BCR (D1.3) (Williams et al., 1994) were a kind gift from Prof Facundo Batista (the Ragon Institute of MGH,
MIT and Harvard, USA). A20 D1.3s were maintained in complete RPMI (cRPMI; RPMI 1640 with $2.05 \mathrm{mM} \mathrm{L-}$ glutamine supplemented with $10 \%$ fetal calf serum (FCS), $4 \mathrm{mM}$ L-glutamine, $50 \mu \mathrm{M} \beta$-mercaptoethanol, $10 \mathrm{mM}$ HEPES and $100 \mathrm{U} / \mathrm{ml}$ penicillin/streptomycin). Raji D1.3s were maintained in Raji cRPMI (RPMI 1640 with $2.05 \mathrm{mM}$ L-glutamine supplemented with 10\% FCS, $4 \mathrm{mM}$ L-glutamine and $100 \mathrm{U} / \mathrm{ml}$ penicillin/streptomycin).

Generation of raft-APEX2 expressing stable cell line. Raft-APEX2-pcDNA ${ }^{\mathrm{TM}} 4 / \mathrm{Zeo} / \mathrm{TO}$ plasmid was transfected into A20 D1.3 cells line as previously described (Šuštar et al., 2018). In brief, 4 million cells were resuspended in $180 \mu \mathrm{l}$ of $2 \mathrm{~S}$ transfection buffer $(5 \mathrm{mM} \mathrm{KCl}$, $15 \mathrm{mM} \mathrm{MgCl}$, $15 \mathrm{mM}$ HEPES, $50 \mathrm{mM}$ Sodium Succinate, $180 \mathrm{mM} \mathrm{Na}_{2} \mathrm{HPO}_{4} / \mathrm{NaH} 2 \mathrm{PO} 4 \mathrm{pH}$ 7.2) containing $10 \mu \mathrm{g}$ of plasmid DNA and electroporated using AMAXA electroporation machine (program X-005, Biosystem) in 0.2 $\mathrm{cm}$ gap electroporation cuvettes. Cells were then transferred to $4 \mathrm{ml}$ of cRPMI containing extra 10\% FCS to recover overnight. Cells were sorted, using Sony SH800 Cell Sorter, single cell/well into 96-well flat bottom plates containing $100 \mu \mathrm{l}$ of cRPMI containing 20\% FCS. Cells were left to recover in cRPMI supplemented with extra $10 \%$ FCS for $48 \mathrm{~h}$ before adding Zeocin $(600 \mu \mathrm{g} / \mathrm{ml}$ final concentration). Clones expressing raft-APEX2 were selected, expanded few weeks after sorting and the expression of raft-APEX2 was verified with flow cytometry analysis for mCherry, V5 and functional biotinylation.

Proximity biotinylation. $10 \times 10^{6}$ A20 D1.3 cells expressing raft-APEX2 were treated with $500 \mu \mathrm{M}$ biotinphenol (BP) (Iris-Biotech, CAS no.: 41994-02-9) for $45 \mathrm{~min}$ and activated with 0 or $10 \mu \mathrm{g} / \mathrm{ml}$ of goat anti-mouse IgM $\mathrm{F}\left(\mathrm{ab}^{\prime}\right)_{2}$ fragments (Jackson ImmunoResearch 115-006-020) for 5, 10 or $15 \mathrm{~min} .1 \mathrm{mM} \mathrm{H}_{2} \mathrm{O}_{2}$ (Sigma-Aldrich, cat. no. H1009-100ML) was added for $1 \mathrm{~min}$ and then quenched with $2 X$ quenching solution ( $20 \mathrm{mM}$ sodium ascorbate, $10 \mathrm{mM}$ Trolox (Sigma-Aldrich, cat. no. 238813-1G) and $20 \mathrm{mM}$ sodium azide solution in PBS). Cells were repeatedly washed 4 time with $1 \mathrm{X}$ quenching solution. Nonbiotinylated control samples were prepared similarly but without anti-IgM and $\mathrm{H}_{2} \mathrm{O}_{2}$. Background control samples were prepared similarly but without BP and anti-IgM. To validate biotinylation for each experiment we used flow cytometry, where cells were fixed, permeabilised and stained with streptavidin 633 (Thermo Fischer Scientific). Samples were lysed with modified RIPA buffer $(50 \mathrm{mM}$ Tris, $150 \mathrm{mM} \mathrm{NaCl}, 0.1 \%$ SDS, 2\% Octyl glucoside (SigmaAldrich, 29836-26-8), 0.5\% sodium deoxycholate and 1\% Triton X-100, pH 7.5) with $1 \times$ protease phosphatase inhibitor mini tablet (1 tablet/10 ml, Thermo Fisher Scientific, cat. no. A32961). Lysate concentrations were measured using Pierce $660 \mathrm{~nm}$ protein assay (Thermo Fisher 
Scientific, cat. no. 22660), aliquoted into $360 \mu \mathrm{g}$ of total protein/aliquot, snap frozen and stored at $-80{ }^{\circ} \mathrm{C}$.

Streptavidin pull-down of biotinylated proteins. $350 \mu \mathrm{g}$ of whole lysate diluted in additional $500 \mu \mathrm{l}$ of RIPA buffer ( $50 \mathrm{mM}$ Tris, $150 \mathrm{mM} \mathrm{NaCl}, 0.1 \% \mathrm{SDS}, 0.5 \%$ sodium deoxycholate and $1 \%$ Triton $\mathrm{X}-100, \mathrm{pH} 7.5,1 \times$ protease phosphatase inhibitor mini tablet) was incubated with 30 $\mu \mathrm{l}(0.3 \mathrm{mg}$ ) of streptavidin magnetic beads (Pierce, cat. no. $88817)$ for $1 \mathrm{~h}$ at RT on rotation. Beads were washed several times with $1 \mathrm{ml}$ volumes for $5 \mathrm{~min}$ each, on ice, as follows: twice with RIPA buffer, twice with $1 \mathrm{M} \mathrm{KCl}$, twice with $0.1 \mathrm{M} \mathrm{Na} 2 \mathrm{CO} 3$, once with $4 \mathrm{M}$ urea in $10 \mathrm{mM}$ Tris$\mathrm{HCl} \mathrm{pH} 8.0$, once with $50 \mu \mathrm{M}$ biotin, $4 \mathrm{M}$ urea in $10 \mathrm{mM}$ Tris- $\mathrm{HCl} \mathrm{pH}$ 8.0, and three times with RIPA buffer. Biotinylated proteins were eluted by boiling the beads in 30 $\mu \mathrm{l}$ of $3 \times$ SDS loading buffer supplemented with $2 \mathrm{mM}$ biotin and $20 \mathrm{mM}$ DTT for $10 \mathrm{~min}$.

In-gel Digestion. Eluted samples were run on 10\% SDS-PAGE and the gel was stained with SimplyBlue SafeStain (ThermoFisher Scientific, cat. no. LC6065). For the digestion, the protocol adapted from Shevchenko et al. was used (Shevchenko et al., 2007). Each gel lane was cut into 4 pieces that were washed twice with $200 \mu \mathrm{l}$ of $0.04 \mathrm{M} \mathrm{NH}_{4} \mathrm{HCO}_{3} / 50 \%$ Acetonitrile $(\mathrm{ACN})$ and dehydrated with $200 \mu \mathrm{l} 100 \% \mathrm{ACN}$. Then, gel pieces were rehydrated in $200 \mu \mathrm{l}$ of $20 \mathrm{mM}$ DTT and dehydrated again as above. Gel pieces were then rehydrated with $100 \mu \mathrm{l}$ $55 \mathrm{mM}$ Iodoacetamide for $20 \mathrm{~min}$ in the dark, RT, washed twice with $100 \mu \mathrm{ll} 100 \mathrm{mM} \mathrm{NH}_{4} \mathrm{HCO}_{3}$ and dehydrated as above. $30 \mu \mathrm{l}$ of $0.02 \mu \mathrm{g} / \mu \mathrm{l}$ of trypsin (Promega V5111) solution was added to the gel pieces for $20 \mathrm{~min}$ followed by addition of $60 \mu \mathrm{l}$ solution containing $40 \mathrm{mM} \mathrm{NH} \mathrm{NHCO}_{3}$ / $10 \%$ ACN to completely cover the gel pieces and the samples were incubated at $37^{\circ} \mathrm{C}$ for $18 \mathrm{~h}$. Peptides were extracted using $90 \mu \mathrm{l}$ of $\mathrm{ACN}$ followed by $150 \mu \mathrm{l}$ of $50 \%$ $\mathrm{ACN} / 5 \% \mathrm{HCOOH}$ at $37^{\circ} \mathrm{C}$ for $15 \mathrm{~min}$.

Mass spectrometry analysis. Data were collected by LC-ESI-MS/MS using a nanoflow HPLC system (EasynLC1200, ThermoFisher Scientific) coupled to the Orbitrap Fusion Lumos mass spectrometer (Thermo Fisher Scientific, Bremen, Germany) equipped with a nanoelectrospray ionisation source. Peptides were first loaded on a trapping column and subsequently separated inline on a $15 \mathrm{~cm} \mathrm{C} 18$ column. A linear 20 min gradient from 8 to $39 \%$ was used to elute peptides. MS data was acquired using Thermo Xcalibur 3.1 software (Thermo Fisher Scientific). A data dependent acquisition method that consists of comprising an Orbitrap MS survey scan of mass range $300-2000 \mathrm{~m} / \mathrm{z}$ followed by HCD fragmentation was used.

Protein Identification. The raw MS data were processed using MaxQuant software version 1.6.0.1 (Cox $\mathcal{E}$ Mann, 2008). MS/MS spectra were searched against mouse UniProt (reviewed (Swiss-Prot), released Septem- ber 2019) using Andromeda search engine (Cox et al., 2011). The following configuration was used for MaxQuant search: Digestion set to trypsin, maximum number of missed cleavages allowed set to 2 , fixed modification set to Carbamidomethyl and variable modifications set to N-terminal acetylation and methionine oxidation. Peptide and protein false discovery rate were set to 0.01 . Match between runs was enabled. MaxLFQ that enables determination of relative intensity values of proteins and also normalise proteins intensity between samples was enabled but not used in downstream analysis (Cox et al., 2014). After MaxQuant run, 2526 proteins were identified, from which contaminants and reverse hits were removed. For further analysis, only the proteins identified with at least 2 unique peptides were considered identified (1677 proteins). The identified proteins were then classified using both KEGG pathway analysis (Kanehisa et al., 2016) and gene ontology (GO) classification (Ashburner et al., 2000). The proteomic data set generated in this work will be submitted to PRIDE (Vizcaíno et al., 2016).

Proteomics and differential enrichment analysis. Normalisation and differential enrichment analysis were done using NormalyzerDE (Willforss et al., 2019) tools in Bioconductor. Quantile normalisation was selected as the best normalisation method following comparison of various normalisation methods in NormalyzerDE (data not shown). Prior to normalisation and differential expression analysis, identified proteins with missing values $\geq 7$ out of 18 conditions were filtered out. For the remaining proteins, missing value imputation was done using k-Neareast Neighbor (kNN) Imputation. Differential enrichment analysis was done using NormalyzerDE with statistical comparison method set to limma, logTrans set to FALSE, leastRepCount set to 1 and sigThresType set to FDR (Benjamini-Hochberg corrected p-values). To identify proteins that are likely raft-resident a strategy adapted from Paek et al., 2017 was used (Paek et al., 2017). We first selected proteins with $\geq 1.5 \log _{2}$ fold-change in nonactivated biotinylated sample compared to control samples (sample without $\mathrm{H}_{2} \mathrm{O}_{2}$ triggered biotinylation). Then, proteins that show $\log _{2}$ foldchange $\geq 1$ in surrogate antigen stimulated samples compared to non-activated samples were filtered out. The list of the proposed raftresident proteins was compared with previously published mammalian lipid raft proteins available in RaftProt database (https:/ / raftprot.org/) (Mohamed et al., 2019).

Bioinformatics analysis. All downstream analysis were carried out with R. Enhancedvolcano, which was used to generate volcano plots (Blighe et al., 2018). Enrichment analysis was done using $\mathrm{R}$ clusterProfiler package (Yu et al., 2012). UpSet plot was constructed to show intersect between conditions. A Venn diagram was constructed 
bioRxiv preprint doi: https://doi.org/10.1101/2020.09.29.318766; this version posted March 5, 2021. The copyright holder for this preprint

(which was not certified by peer review) is the author/funder, who has granted bioRxiv a license to display the preprint in perpetuity. It is made APEX2 proximity proteomics of B cell activation available under aCC-BY-ND 4.0 International license.

to depict intersect of proteins significantly enriched upon $\mathrm{BCR}$ cross-linking at different time points.

Western blotting. Raft-APEX2 A20 D1.3 cells were starved for $20 \mathrm{~min}$ in serum-free media and incubated with either $10 \mu \mathrm{g} / \mathrm{ml}$ of goat anti-mouse $\operatorname{IgM~F}\left(\mathrm{ab}^{\prime}\right)_{2}$ fragments (Jackson ImmunoResearch 115-006-020) for $10 \mathrm{~min}$ or $0.1 \mathrm{mM}, 1 \mathrm{mM}$ and $10 \mathrm{mM} \mathrm{H}_{2} \mathrm{O}_{2}$ for $1 \mathrm{~min}$. After which cells were lysed with $2 x$ SDS PAGE loading buffer, sonicated and proceeded to SDS gel and Western blotting, probed with streptavidin-HRP (Life Technologies, cat. no. S-911).

Detergent Resistance Membrane analysis by flow cytometry. A20D1.3 cells were electroporated with raftAPEX2, GFP fused with GPI-anchored decay-accelerating factor (CD55) glycosyl phosphatidylinositol (GPI-DAF) (Legler et al., 2005) as a raft marker, or GFP fused to influenza virus hemagglutinin transmembrane domain (TDM) (Nikolaus et al., 2010) as a non-raft marker. The assay was performed according to Gombos (Gombos et al., 2004). In short: 24 hours after transfection cells were incubated with Atto633-labeled Fab fragments of anti-mouse IgM (Jackson ImmunoResearch 115-007-020) on ice for 15 $\mathrm{min}$, then the sample was split for activation with or without $1 \mu \mathrm{g} / \mathrm{ml}$ of HEL for $10 \mathrm{~min}$ at $37{ }^{\circ} \mathrm{C}$, and precooled on ice for $5 \mathrm{~min}$. The samples were divided for incubation in 0 or $0.1 \%$ Triton X-100 in Imaging Buffer, 5 min on ice, to preserve or release the proteins bound to the nonraft domains. Final concentration of $1 \%$ of paraformaldehyde was added and the cells were kept on ice until analysed by flow cytometry. The parameter of detergent resistance was calculated as DRI $=\left(\mathrm{FL}_{\mathrm{det}}-\mathrm{FLBg}_{\mathrm{det}}\right) /\left(\mathrm{FL}_{\max }-\right.$ FLBg), where $\mathrm{FL}_{\text {det }}$ stands for fluorescence of the cells treated with detergent for $5 \mathrm{~min}, \mathrm{FLBg}_{\mathrm{det}}$ for autofluorescence of the detergent-treated cells, $\mathrm{FL}_{\max }$ for fluorescence of labelled untreated cells (proportional to the protein expression level), FLBg for autofluorescence (background) of the unlabelled cells. The experiment was repeated at least 7 times for each marker in non-activated cells and 3 times for activated cells.

AiryScan confocal microscopy to analyse raftAPEX2 localisation. Glass-bottom microscopy chambers (Mattek) were coated with $4 \mu \mathrm{g} / \mathrm{ml}$ fibronectin in PBS for $1 \mathrm{~h} \mathrm{RT}$ and washed with PBS. Similarly to the mass spectrometry samples, cells were incubated in $500 \mu \mathrm{M}$ BP in complete medium at $37{ }^{\circ} \mathrm{C}$ for $45 \mathrm{~min}$. The cells were then let to settle on the microscopy chambers at $37{ }^{\circ} \mathrm{C}$ for $15 \mathrm{~min}$ and incubated with $1 \mathrm{mM} \mathrm{H}_{2} \mathrm{O}_{2}$ together with $4 \%$ paraformaldehyde and $0.1 \%$ glutaraldehyde to immediately fix the sample, washed and continued to fix for further $10 \mathrm{~min}$. Cells were washed, blocked in blocking buffer (BSA + goat serum) at RT for $1 \mathrm{~h}$, labelled with Atto488-labelled WGA, washed, permeabilised with $0.1 \%$ Triton X-100, at RT for $5 \mathrm{~min}$, blocked again, and la- belled with streptavidin-Alexa Fluor® (AF)-633 (1:2000) and DAPI at RT for $1 \mathrm{~h}$. After washing, the samples were mounted in Vectashield. For visualisation of raftAPEX2 upon BCR activation, after settling, $1 \mu \mathrm{g} / \mathrm{ml}$ of HEL antigen was added on ice, then incubated at $37{ }^{\circ} \mathrm{C}$ for $5 \mathrm{~min}$ and fixed for processing as above with exception of staining with Atto488-labelled goat anti-mouse IgM $\mathrm{F}\left(\mathrm{ab}^{\prime}\right)_{2}$ fragments (Jackson ImmunoResearch 115-006-020) instead of WGA-Atto488. Images were acquired using a laser scanning confocal microscope LSM880 (Zeiss) with an Airyscan detector (32-channel Airyscan Hexagonal element) equipped with 405 (Diode), 488 (Argon) and 633 $(\mathrm{HeNe})$ laser lines and an oil-immersion 63× Zeiss PlanApochromat objective. Images were acquired using the standard super-resolution mode (Zen Black 2.3). The profile intensity analysis was done in Fiji ImageJ (NIH).

\section{Immunofluorescence sample preparation for Vti1b} and Golga3. 8-well polymer coverslips ( $\mu$-Slide 8, high-well, IBIDI 80806) were coated with CellTak substrate (CellTak, Corning ${ }^{\circledR}$, purchased from Sigma-Aldrich DLW354242) according to the manufacturer's recommendations. In short, $80 \mu \mathrm{l}$ of $56 \mu \mathrm{g} / \mathrm{ml}$ CellTak in $\mathrm{H}_{2} \mathrm{O}$ was applied in each well. CellTak was topped with $120 \mu \mathrm{l}$ of $0.1 \mathrm{M} \mathrm{NaHCO} 3 \mathrm{pH}$ 8.0. to activate the reaction. The slides were incubated for $1-2 \mathrm{~h}$ at $\mathrm{RT}$, washed $1 \mathrm{x}$ with $\mathrm{H}_{2} \mathrm{O}$, dried and stored at $+4^{\circ} \mathrm{C}$. 150.000 Raji D1.3 cells that were either non activated or activated with $5 \mathrm{\mu g} / \mathrm{ml}$ of HEL (SigmaAldrich, 10837059001) or $10 \mu \mathrm{g} / \mathrm{ml}$ AF-488/-647 labelled $\mathrm{F}\left(\mathrm{ab}^{\prime}\right)_{2}$ Fragments of donkey anti-mouse IgM (Jackson ImmunoResearch 715-546-020 / 715-606-020), were placed in $300 \mu \mathrm{l}$ of imaging buffer (10\% FCS in PBS) on coverslip wells and left in the incubator $\left(5 \% \mathrm{CO}_{2},+37^{\circ} \mathrm{C}\right)$ for 15 minutes. The cells were fixed with 50:50 methanolacetone at $-20^{\circ} \mathrm{C}$ for $20 \mathrm{~min}$, permeabilised with acetone for 5 minutes at $-20^{\circ} \mathrm{C}$, and blocked $(5 \%$ donkey serum in PBS) for 1-2 $\mathrm{h}$ at RT. The cells were stained with primary antibodies in PBS supplemented with 5\% bovine serum albumin overnight in $+4^{\circ} \mathrm{C}$, washed three times with PBS and incubated with secondary antibodies in PBS for 1-2 $h$ at RT, and washed three times with PBS. Samples were mounted with FluoroMount-G containing DAPI (Thermo FisherScientific 00495952). For immunostainings, anti-alpha-Tubulin AF488/-647 (mouse IgG1monoclonal [DM1A], Merc Millipore, Sigma-Aldrich 16232 / 05-829-AF647) was used at the dilution of 1:150, anti-Vti1b (rabbit IgG-monoclonal [EPR15506(B)], Abcam ab184170) was used at 1:100 and anti-Golga3 (rabbit IgGpolyclonal, Atlas antibodies, Sigma-Adrich HPA040044) was used at 1:150. Anti-HEL antibody (F10, mouse IgG1) was a kind gift from Prof Facundo Batista (the Ragon Institute of MGH, MIT and Harvard, USA). Secondary antibodies anti-mouse IgG1 AF488/-647 (Goat Anti-Mouse IgG, Fcr subclass 1-specific, Jackson ImmunoResearch 
115-545-205 / 115-605-205) and anti-Rabbit IgG AF555 (Donkey anti-Rabbit IgG (H+L), Invitrogen A-31572) were used at 1:500.

Spinning disc confocal image acquisition, processing and analysis. Images were acquired using a 3i CSU-W1 spinning disk confocal microscope (SDCM) equipped with 405, 488, 561 and $640 \mathrm{~nm}$ laser lines and 510-540, 580-654 and 672-712 nm filters, 63× Zeiss Plan-Apochromat objective, and Hamamatsu sCMOS OrcaFlash4 v2 IC11440-22CU $(2048 \times 2048$ pixels, $1 \times 1$ binning) camera. SDCM images were deconvoluted with Huygens Essential version16.10 (Scientific Volume Imaging, The Netherlands, http://svi.nl), using automated algorithms and thresholded optimally, yet consistently. Particle analysis was done with Huygens Essential. In Golga3-particle analysis, intensity values of $<5 \%$ of the maximum were considered as background. In Golga3particle analysis, Tubulin channel was used to define cell outlines in 3D that were then shrank by $0.27 \mu \mathrm{m}$, corresponding to 1 pixel along Z-axis. Intensities inside the $3 \mathrm{D}$ selection were cleared resulting in the remaining hollow sphere comprising the cell periphery only. Peripheral Golga3 particles were then automatically analysed. Colocalisation between Golga3 and antigen was analysed with Huygens Essential, also from the peripheral spheres, using optimised, automatic thresholding. In the Vtilbparticle analysis, intensity values of $<3 \%$ of the maximum were considered as background. Here, tubulin staining was not possible due to the antibody cross-over, so the whole cell volumes were analysed. Nucleus' center of mass was determined as the reference point when CMCM (nucleus' center of mass - particles' center of mass) was calculated. Colocalisation between VTI1b and antigen was analysed with Huygens Essential.
Statistics and illustrations. Graphs and statistics were prepared with GraphPad Prism 6 (GraphPad Software, La Jolla, CA). Statistical significances were calculated using unpaired Student's t-test assuming normal distribution of the data. Statistical values are denoted as: ${ }^{*} \mathrm{P}<0.05,{ }^{* *} \mathrm{P}<0.01,{ }^{* * *} \mathrm{P}<0.001,{ }^{* * * *} \mathrm{P}<0.0001$. Illustrations were created with BioRender. Figure formatting was undertaken in Inkscape v.092.2.

Author Contributions: L.O.A., M.R., S.H-P., V.Š., A.V.S., P.P and P.K.M. conceived and designed the analysis. L.O.A., M.R., S.H-P. and V.Š. collected the data. L.O.A., M.R., S.H-P., V.Š., A.V.S., P.P and P.K.M. contributed or performed the data analysis. L.O.A., M.R., S.H-P. and P.P. visualised the data. L.O.A., M.R., S.H-P. and P.K.M. wrote the paper.

Funding: This work was supported by the Academy of Finland (grant ID: 25700, 296684 and 307313; to P.K.M., and 286712 for V.Š), Sigrid Juselius and Jane and Aatos Erkko foundations (to P.K.M), Finnish Cultural foundations (to S.H-P. and VŠ), Turku Doctoral Programme in Molecular Medicine (TuDMM) (to L.O.A., M.R. and S.H-P.), and Turku University foundation (to L.O.A., M.R. and S.H-P.).

Acknowledgments: We thank Laura Grönfors, Johanna Rajala and Citarra Burrows for technical help. Mass spectrometry analysis was performed at the Turku Proteomics Facility, University of Turku and Åbo Akademi University. Anne Rokka and the staff of the proteomics facility is acknowledged for their help in mass spectrometry analysis. Microscopy and flow cytometry were performed at Turku Bioscience Cell Imaging and Cytometry (CIC), supported by Turku Bioimaging and EuroBioimaging. Their personnel is thanked for generous help and expertise. Biocenter Finland is acknowledged for providing research infrastructures.

Conflicts of Interest: The authors declare no conflict of interest.

\section{References}

Aluvihare, V. R., Khamlichi, A. A., Williams, G. T., Adorini, L., \& Neuberger, M. S. (1997). Acceleration of intracellular targeting of antigen by the B-cell antigen receptor: Importance depends on the nature of the antigen-antibody interaction. EMBO Journal, 16(12), 3553-3562.

Aman, M. J., \& Ravichandran, K. S. (2000). A requirement for lipid rafts in B cell receptor induced Ca2+ flux. Current Biology, 10(7), 393-396.

Antonin, W., Holroyd, C., Fasshauer, D., Pabst, S., Von Mollard, G. F., \& Jahn, R. (2000). A SNARE complex mediating fusion of late endosomes defines conserved properties of SNARE structure and function. EMBO Journal, 19(23), 6453-6464.

Ashburner, M., Ball, C. A., Blake, J. A., Botstein, D., Butler, H., Cherry, J. M., Davis, A. P., Dolinski, K., Dwight, S. S., Eppig, J. T., Harris, M. A., Hill, D. P., Issel-Tarver, L., Kasarskis, A.,
Lewis, S., Matese, J. C., Richardson, J. E., Ringwald, M., Rubin, G. M., \& Sherlock, G. (2000). Gene ontology: Tool for the unification of biology. Nature Genetics, 25(1), 25-29.

Ban, T., Sato, G. R., Nishiyama, A., Akiyama, A., Takasuna, M., Umehara, M., Suzuki, S., Ichino, M., Matsunaga, S., Kimura, A., Kimura, Y., Yanai, H., Miyashita, S., Kuromitsu, J., Tsukahara, K., Yoshimatsu, K., Endo, I., Yamamoto, T., Hirano, H., Ryo, A., Taniguchi, T., \& Tamura, T. (2016). Lyn Kinase Suppresses the Transcriptional Activity of IRF5 in the TLR-MyD88 Pathway to Restrain the Development of Autoimmunity. Immunity, 45(2), 319-332.

Bareja, A., Hodgkinson, C. P., Soderblom, E., Waitt, G., \& Dzau, V. J. (2018). The proximity-labeling technique BioID identifies sorting nexin 6 as a member of the insulin-like growth factor 1 (IGF1)-IGF1 receptor pathway. Journal of Biological Chemistry, 293(17), 6449-6459. 
Bécart, S., Balancio, A. J., Charvet, C., Feau, S., Sedwick, C. E., \& Altman, A. (2008). Tyrosine-Phosphorylation-Dependent Translocation of the SLAT Protein to the Immunological Synapse Is Required for NFAT Transcription Factor Activation. Immunity, 29(5), 704-719.

Bi, K., Tanaka, Y., Coudronniere, N., Sugie, K., Hong, S., Van Stipdonk, M. J., \& Altman, A. (2001). Antigen-induced translocation of PKC- $\theta$ to membrane rafts is required for $\mathrm{T}$ cell activation. Nature Immunology, 2(6), 556-563.

Blighe, K., Rana, S., \& Lewis, M. (2018). EnhancedVolcano: Publication-ready volcano plots with enhanced colouring and labeling Title. https://github.com/kevinblighe/EnhancedVolcano.

Bosch, J. A., Chen, C. L., \& Perrimon, N. (2021). Proximitydependent labeling methods for proteomic profiling in living cells: An update.

Brunet, A., Bonni, A., Zigmond, M. J., Lin, M. Z., Juo, P., Hu, L. S., Anderson, M. J., Arden, K. C., Blenis, J., \& Greenberg, M. E. (1999). Akt promotes cell survival by phosphorylating and inhibiting a forkhead transcription factor. Cell, 96(6), 857868.

Chen, C. L., \& Perrimon, N. (2017). Proximity-dependent labeling methods for proteomic profiling in living cells. Wiley Interdisciplinary Reviews: Developmental Biology, 6(4).

Cheng, P. C., Dykstra, M. L., Mitchell, R. N., \& Pierce, S. K. (1999). A role for lipid rafts in $\mathrm{B}$ cell antigen receptor signaling and antigen targeting. Journal of Experimental Medicine, 190(11), 1549-1560.

Chou, H. Y., Lee, Y. T., Lin, Y. J., Wen, J. K., Peng, W. H., Hsieh, P. L., Lin, S. Y., Hung, C. C., \& Chen, G. C. (2020). PTPN9mediated dephosphorylation of VTI1B promotes ATG16L1 precursor fusion and autophagosome formation. Autophagy.

Cox, J., Hein, M. Y., Luber, C. A., Paron, I., Nagaraj, N., \& Mann, M. (2014). Accurate proteome-wide label-free quantification by delayed normalization and maximal peptide ratio extraction, termed MaxLFQ. Molecular and Cellular Proteomics, 13(9), 2513-2526.

Cox, J., \& Mann, M. (2008). MaxQuant enables high peptide identification rates, individualized p.p.b.-range mass accuracies and proteome-wide protein quantification. Nature Biotechnology, 26(12), 1367-1372.

Cox, J., Neuhauser, N., Michalski, A., Scheltema, R. A., Olsen, J. V., \& Mann, M. (2011). Andromeda: A peptide search engine integrated into the MaxQuant environment. Journal of Proteome Research, 10(4), 1794-1805.

Depoil, D., Fleire, S., Treanor, B. L., Weber, M., Harwood, N. E., Marchbank, K. L., Tybulewicz, V. L., \& Batista, F. D. (2008). CD19 is essential for B cell activation by promoting $B$ cell receptor-antigen microcluster formation in response to membrane-bound ligand. Nature Immunology, 9(1), 63-72.

Doerr, A. (2018). Proximity labeling with TurboID. Nature Methods, 15(10), 764 .
Dressel, R., Elsner, L., Novota, P., Kanwar, N., \& Fischer von Mollard, G. (2010). The Exocytosis of Lytic Granules Is Impaired in Vti1b- or Vamp8- Deficient CTL Leading to a Reduced Cytotoxic Activity following Antigen-Specific Activation. The Journal of Immunology, 185(2), 1005-1014.

Dumin, E., Bendikov, I., Foltyn, V. N., Misumi, Y., Ikehara, Y., Kartvelishvily, E., \& Wolosker, H. (2006). Modulation of Dserine levels via ubiquitin-dependent proteasomal degradation of serine racemase. Journal of Biological Chemistry, 281(29), 20291-20302.

Gombos, I., Bacsó, Z., Detre, C., Nagy, H., Goda, K., Andrásfalvy, M., Szabó, G., \& Matkó, J. (2004). Cholesterol sensitivity of detergent resistance: A rapid flow cytometric test for detecting constitutive or induced raft association of membrane proteins. Cytometry Part A, 61(2), 117-126.

Gupta, N., \& DeFranco, A. L. (2003). Visualizing lipid raft dynamics and early signaling events during antigen receptormediated B-lymphocyte activation. Molecular Biology of the Cell, 14(2), 432-444.

Gupta, N., Wollscheid, B., Watts, J. D., Scheer, B., Aebersold, R., \& DeFranco, A. L. (2006). Quantitative proteomic analysis of $B$ cell lipid rafts reveals that ezrin regulates antigen receptormediated lipid raft dynamics. Nature Immunology, 7(6), 625633.

Hao, J. J., Carey, G. B., \& Zhan, X. (2004). Syk-mediated tyrosine phosphorylation is required for the association of hematopoietic lineage cell-specific protein 1 with lipid rafts and B cell antigen receptor signalosome complex. Journal of Biological Chemistry, 279(32), 33413-33420.

Harwood, N. E., \& Batista, F. D. (2010). Early events in B cell activation.

Hernández-Pérez, S., Vainio, M., Kuokkanen, E., Šuštar, V., Petrov, P., Forstén, S., Paavola, V., Rajala, J., Awoniyi, L. O., Sarapulov, A. V., Vihinen, H., Jokitalo, E., Bruckbauer, A., \& Mattila, P. K. (2020). B cells rapidly target antigen and surfacederived MHCII into peripheral degradative compartments. Journal of Cell Science, 133(5).

Hicks, S. W., Horn, T. A., Mccaffery, J. M., Zuckerman, D. M., \& Machamer, C. E. (2006). Golgin-160 promotes cell surface expression of the beta-1 adrenergic receptor. Traffic, 7(12), 16661677.

Hicks, S. W., \& Machamer, C. E. (2005). Isoform-specific interaction of golgin-160 with the Golgi-associated protein PIST. Journal of Biological Chemistry, 280(32), 28944-28951.

Huang, D. W., Sherman, B. T., \& Lempicki, R. A. (2009a). Bioinformatics enrichment tools: Paths toward the comprehensive functional analysis of large gene lists. Nucleic Acids Research, 37(1), 1-13.

Huang, D. W., Sherman, B. T., \& Lempicki, R. A. (2009b). Systematic and integrative analysis of large gene lists using DAVID bioinformatics resources. Nature Protocols, 4(1), 44-57.

Huff, J. (2015). The Airyscan detector from ZEISS: confocal imaging with improved signal-to-noise ratio and super-resolution. Nature Methods, 12(12), i-ii. 
Hung, V., Udeshi, N. D., Lam, S. S., Loh, K. H., Cox, K. J., Pedram, K., Carr, S. A., \& Ting, A. Y. (2016). Spatially resolved proteomic mapping in living cells with the engineered peroxidase APEX2. Nature Protocols, 11(3), 456-475.

Hung, V., Zou, P., Rhee, H. W., Udeshi, N. D., Cracan, V., Svinkina, T., Carr, S. A., Mootha, V. K., \& Ting, A. Y. (2014). Proteomic Mapping of the Human Mitochondrial Intermembrane Space in Live Cells via Ratiometric APEX Tagging. Molecular Cell, 55(2), 332-341.

Kanehisa, M., Sato, Y., Kawashima, M., Furumichi, M., \& Tanabe, M. (2016). KEGG as a reference resource for gene and protein annotation. Nucleic Acids Research, 44(D1), D457-D462.

Kreykenbohm, V., Wenzel, D., Antonin, W., Atlachkine, V., \& Fischer Von Mollard, G. (2002). The SNAREs vtila and vti1b have distinct localization and SNARE complex partners. European Journal of Cell Biology, 81(5), 273-280.

Kuokkanen, E., Šuštar, V., \& Mattila, P. K. (2015). Molecular control of $\mathrm{B}$ cell activation and immunological synapse formation. Traffic, 16(4), 311-326.

Kwak, K., Akkaya, M., \& Pierce, S. K. (2019). B cell signaling in context. Nature Immunology, 20(8), 963-969.

Lam, S. S., Martell, J. D., Kamer, K. J., Deerinck, T. J., Ellisman, M. H., Mootha, V. K., \& Ting, A. Y. (2015). Directed evolution of APEX2 for electron microscopy and proximity labeling. $\mathrm{Na}$ ture Methods, 12(1), 51-4.

Legler, D. F., Doucey, M.-A., Schneider, P., Chapatte, L., Bender, F. C., \& Bron, C. (2005). Differential insertion of GPI-anchored GFPs into lipid rafts of live cells. The FASEB Journal, 19(1), 73-75.

Li, X. W., Rees, J. S., Xue, P., Zhang, H., Hamaia, S. W., Sanderson, B., Funk, P. E., Farndale, R. W., Lilley, K. S., Perrett, S., \& Jackson, A. P. (2014). New insights into the DT40 B cell receptor cluster using a proteomic proximity labeling assay. Journal of Biological Chemistry, 289(21), 14434-14447.

Liem, R. K. (2016). Cytoskeletal integrators: The spectrin superfamily.

Maag, R. S., Mancini, M., Rosen, A., \& Machamer, C. E. (2005). Caspase-resistant golgin-160 disrupts apoptosis induced by secretory pathway stress and ligation of death receptors. Molecular Biology of the Cell, 16(6), 3019-3027.

Margiotta, A., Frei, D. M., Sendstad, I. H., Janssen, L., Neefjes, J., \& Bakke, O. (2021). Invariant chain regulates endosomal fusion and maturation through an interaction with the SNARE Vti1b. Journal of Cell Science, 133(19).

Martin, B. R., \& Cravatt, B. F. (2009). Large-scale profiling of protein palmitoylation in mammalian cells. Nature Methods, 6(2), 135-138.

Matsumoto, M., Oyamada, K., Takahashi, H., Sato, T., Hatakeyama, S., \& Nakayama, K. I. (2009). Large-scale proteomic analysis of tyrosine-phosphorylation induced by T-cell receptor or B-cell receptor activation reveals new signaling pathways. Proteomics, 9(13), 3549-3563.
Mattila, P. K., Batista, F. D., \& Treanor, B. (2016). Dynamics of the actin cytoskeleton mediates receptor cross talk: An emerging concept in tuning receptor signaling.

Mattila, P. K., Feest, C., Depoil, D., Treanor, B., Montaner, B., Otipoby, K. L., Carter, R., Justement, L. B., Bruckbauer, A., \& Batista, F. D. (2013). The Actin and Tetraspanin Networks Organize Receptor Nanoclusters to Regulate B Cell ReceptorMediated Signaling. Immunity, 38(3), 461-474.

Mick, D. U., Rodrigues, R. B., Leib, R. D., Adams, C. M., Chien, A. S., Gygi, S. P., \& Nachury, M. V. (2015). Proteomics of Primary Cilia by Proximity Labeling. Developmental Cell, 35(4), 497-512.

Mielenz, D., Vettermann, C., Hampel, M., Lang, C., Avramidou, A., Karas, M., \& Jäck, H.-M. (2005). Lipid Rafts Associate with Intracellular B Cell Receptors and Exhibit a B Cell Stage-Specific Protein Composition. The Journal of Immunology, 174(6), 3508-3517.

Mohamed, A., Shah, A. D., Chen, D., \& Hill, M. M. (2019). RaftProt V2: Understanding membrane microdomain function through lipid raft proteomes. Nucleic Acids Research, 47(D1), D459-D463.

Mollinedo, F., \& Gajate, C. (2020). Lipid rafts as signaling hubs in cancer cell survival/death and invasion: Implications in tumor progression and therapy.

Negishi, H., Ohba, Y., Yanai, H., Takaoka, A., Honma, K., Yui, K., Matsuyama, T., Taniguchi, T., \& Honda, K. (2005). Negative regulation of Toll-like-receptor signaling by IRF-4. Proceedings of the National Academy of Sciences of the United States of America, 102(44), 15989-15994.

Nikolaus, J., Scolari, S., Bayraktarov, E., Jungnick, N., Engel, S., Plazzo, A. P., Stöckl, M., Volkmer, R., Veit, M., \& Herrmann, A. (2010). Hemagglutinin of influenza virus partitions into the nonraft domain of model membranes. Biophysical Journal, 99(2), 489-498.

Núñez, M. F., Wisser, K., \& Veatch, S. L. (2020). Synergistic factors control kinase-phosphatase organization in B-cells engaged with supported bilayers. Molecular Biology of the Cell, 31(7), 667-682.

Paek, J., Kalocsay, M., Staus, D. P., Wingler, L., Pascolutti, R., Paulo, J. A., Gygi, S. P., \& Kruse, A. C. (2017). Multidimensional Tracking of GPCR Signaling via Peroxidase-Catalyzed Proximity Labeling. Cell, 169(2), 338-349.e11.

Qin, W., Cho, K. F., Cavanagh, P. E., \& Ting, A. Y. (2021). Deciphering molecular interactions by proximity labeling.

Randall, K. L., Lambe, T., Goodnow, C. C., \& Cornall, R. J. (2010). The essential role of DOCK8 in humoral immunity. Disease Markers, 29(3-4), 141-150.

Razinia, Z., Mäkelä, T., Ylänne, J., \& Calderwood, D. A. (2012). Filamins in mechanosensing and signaling.

Reth, M. (2002). Hydrogen peroxide as second messenger in lymphocyte activation. Nature Immunology, 3(12), 1129-1134. 
Rhee, H. W., Zou, P., Udeshi, N. D., Martell, J. D., Mootha, V. K., Carr, S. A., \& Ting, A. Y. (2013). Proteomic mapping of mitochondria in living cells via spatially restricted enzymatic tagging. Science, 339(6125), 1328-1331.

Roux, K. J., Kim, D. I., Raida, M., \& Burke, B. (2012). A promiscuous biotin ligase fusion protein identifies proximal and interacting proteins in mammalian cells. Journal of Cell Biology, 196(6), 801-810.

Saeki, K., Miura, Y., Aki, D., Kurosaki, T., \& Yoshimura, A. (2003). The B cell-specific major raft protein, Raftlin, is necessary for the integrity of lipid raft and BCR signal transduction. EMBO Journal, 22(12), 3015-3026.

Saito, K., Scharenberg, A. M., \& Kinet, J. P. (2001). Interaction between the Btk PH Domain and Phosphatidylinositol3,4,5-trisphosphate Directly Regulates Btk. Journal of Biological Chemistry, 276(19), 16201-16206.

Samavarchi-Tehrani, P., Samson, R., \& Gingras, A. C. (2020). Proximity dependent biotinylation: Key enzymes and adaptation to proteomics approaches. Molecular and Cellular Proteomics, 19(5), 757-773.

Satpathy, S., Wagner, S. A., Beli, P., Gupta, R., Kristiansen, T. A., Malinova, D., Francavilla, C., Tolar, P., Bishop, G. A., Hostager, B. S., \& Choudhary, C. (2015). Systems-wide analysis of BCR signalosomes and downstream phosphorylation and ubiquitylation. Molecular Systems Biology, 11(6), 810.

Sedwick, C. E., \& Altman, A. (2002). Ordered Just So: Lipid Rafts and Lymphocyte Function. Science Signaling, 2002(122), re2-re2.

Sezgin, E., Levental, I., Mayor, S., \& Eggeling, C. (2017). The mystery of membrane organization: Composition, regulation and roles of lipid rafts.

Sohn, H. W., Tolar, P., Jin, T., \& Pierce, S. K. (2006). Fluorescence resonance energy transfer in living cells reveals dynamic membrane changes in the initiation of B cell signaling. Proceedings of the National Academy of Sciences of the United States of America, 103(21), 8143-8148.

Sohn, H. W., Tolar, P., Pierce, S. K., Hae, W. S., Tolar, P., \& Pierce, S. K. (2008). Membrane heterogeneities in the formation of B cell receptor-Lyn kinase microclusters and the immune synapse. Journal of Cell Biology, 182(2), 367-379.

Stone, M. B., Shelby, S. A., Nńñez, M. F., Wisser, K., \& Veatch, S. L. (2017). Protein sorting by lipid phase-like domains supports emergent signaling function in b lymphocyte plasma membranes. eLife, 6 .

Šuštar, V., Vainio, M., \& Mattila, P. K. (2018). Visualization and quantitative analysis of the actin cytoskeleton upon B cell activation. In Methods in Molecular Biology, vol. 1707, (pp. 243257). Humana Press Inc.
Varshney, P., Yadav, V., \& Saini, N. (2016). Lipid rafts in immune signalling: current progress and future perspective. Immunology, 149(1), 13-24.

Vizcaíno, J. A., Csordas, A., Del-Toro, N., Dianes, J. A., Griss, J., Lavidas, I., Mayer, G., Perez-Riverol, Y., Reisinger, F., Ternent, T., Xu, Q.-W., Wang, R., \& Hermjakob, H. (2016). Erratum: 2016 update of the PRIDE database and its related tools (Nucleic Acids Research (2016) 44:D1 (D447-D456) DOI: 10.1093/nar/gkv1145). Nucleic Acids Research, 44(22), 11033.

Wienands, J., Larbolette, O., \& Reth, M. (1996). Evidence for a preformed transducer complex organized by the B cell antigen receptor. Proceedings of the National Academy of Sciences of the United States of America, 93(15), 7865-7870.

Willforss, J., Chawade, A., \& Levander, F. (2019). NormalyzerDE: Online Tool for Improved Normalization of Omics Expression Data and High-Sensitivity Differential Expression Analysis. Journal of Proteome Research, 18(2), 732-740.

Williams, D., Hicks, S. W., Machamer, C. E., \& Pessin, J. E. (2006). Golgin-160 is required for the Golgi membrane sorting of the insulin-responsive glucose transporter GLUT4 in adipocytes. Molecular Biology of the Cell, 17(12), 5346-5355.

Williams, G. T., Peaker, C. J., Patel, K. J., \& Neuberger, M. S. (1994). The $\alpha / \beta$ sheath and its cytoplasmic tyrosines are required for signaling by the B-cell antigen receptor but not for capping or for serine/threonine- kinase recruitment. Proceedings of the National Academy of Sciences of the United States of America, 91(2), 474-478.

Xu, Y., Harder, K. W., Huntington, N. D., Hibbs, M. L., \& Tarlinton, D. M. (2005). Lyn tyrosine kinase: Accentuating the positive and the negative. Immunity, 22(1), 9-18.

Yadav, S., Puthenveedu, M. A., \& Linstedt, A. D. (2012). Golgin160 Recruits the Dynein Motor to Position the Golgi Apparatus. Developmental Cell, 23(1), 153-165.

Yang, W., Di Vizio, D., Kirchner, M., Steen, H., \& Freeman, M. R. (2010). Proteome scale characterization of human Sacylated proteins in lipid raft-enriched and non-raft membranes. Molecular and Cellular Proteomics, 9(1), 54-70.

Yasuda, K., Kosugi, A., Hayashi, F., Saitoh, S.-i., Nagafuku, M., Mori, Y., Ogata, M., \& Hamaoka, T. (2000). Serine 6 of Lck Tyrosine Kinase: A Critical Site for Lck Myristoylation, Membrane Localization, and Function in T Lymphocytes. The Journal of Immunology, 165(6), 3226-3231.

Yu, G., Wang, L. G., Han, Y., \& He, Q. Y. (2012). ClusterProfiler: An $\mathrm{R}$ package for comparing biological themes among gene clusters. OMICS A Journal of Integrative Biology, 16(5), 284-287. 
bioRxiv preprint doi: https://doi.org/10.1101/2020.09.29.318766; this version posted March 5, 2021. The copyright holder for this preprint (which was not certified by peer review) is the author/funder, who has granted bioRxiv a license to display the preprint in perpetuity. It is made available under aCC-BY-ND 4.0 International license

Awoniyi et al. 2021 | Supplementary Information

\section{Supplementary Information:}

- $\quad$ Supplementary Figures 1-5

- $\quad$ Supplementary Files 1-3 
bioRxiv preprint doi: https://doi.org/10.1101/2020.09.29.318766; this version posted March 5, 2021. The copyright holder for this preprint (which was not certified by peer review) is the author/funder, who has granted bioRxiv a license to display the preprint in perpetuity. It is made

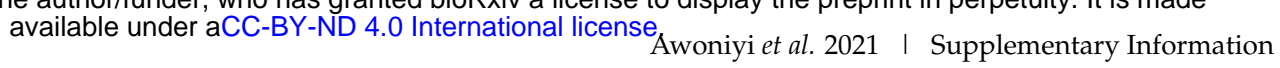

A
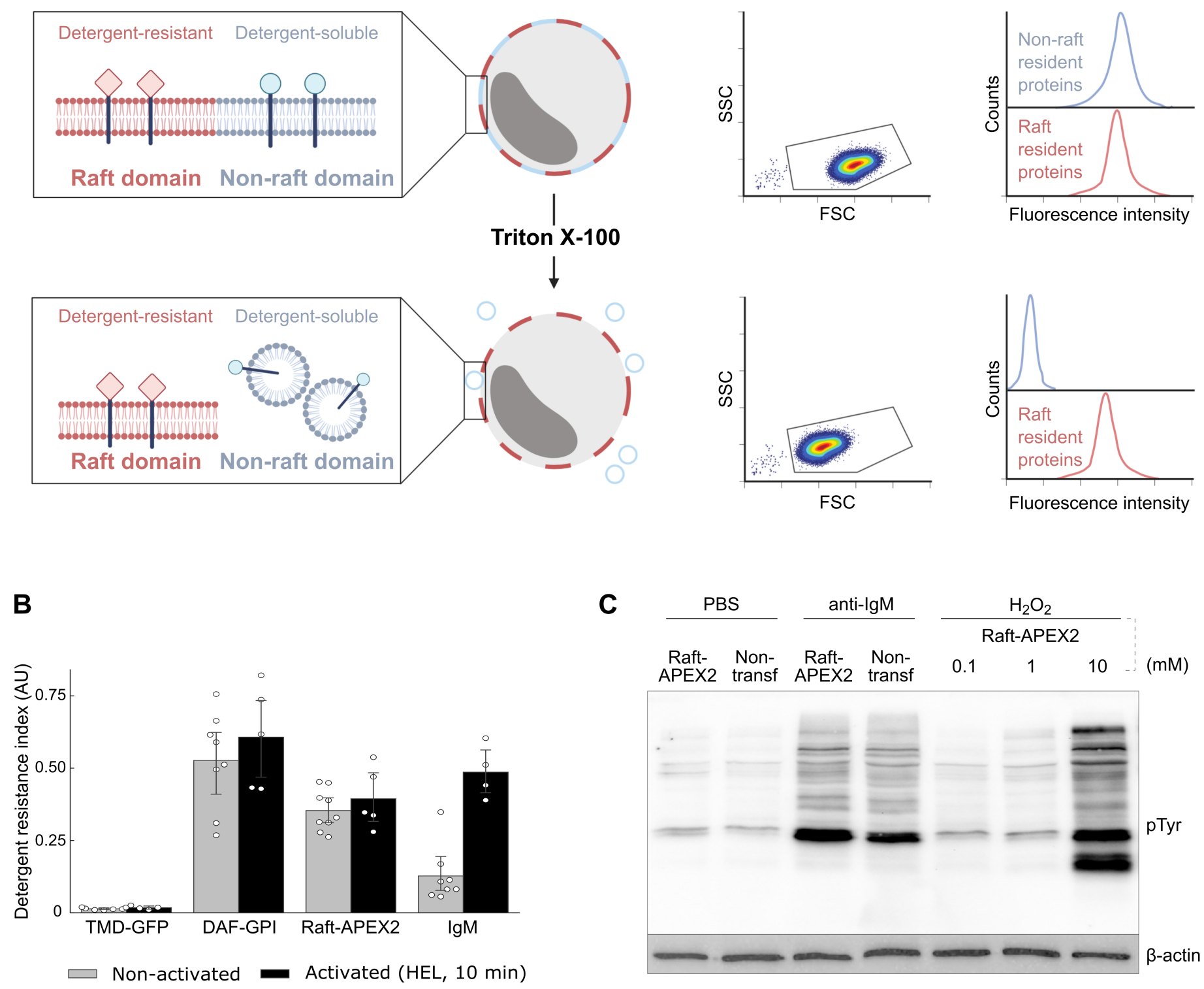

D

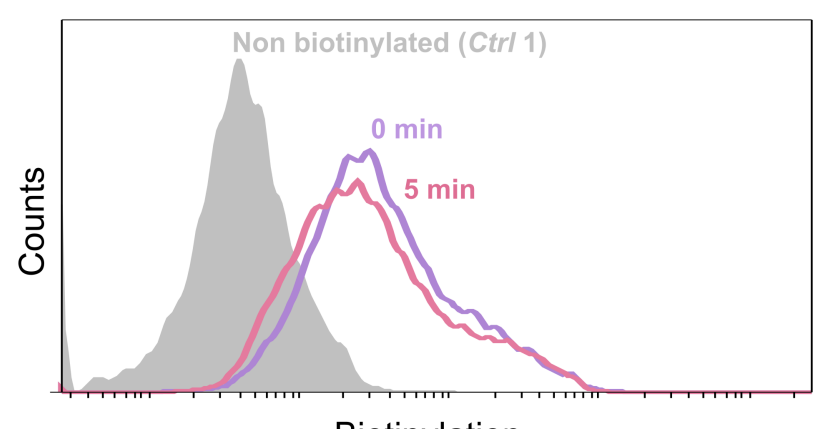

Biotinylation

Figure S1: Raft-APEX2 construct locates in the detergent-resistant membrane domains. A) A schematic representation of flow cytometry assay to detect lipid raft association of membrane proteins by analysis of detergent resistance. Upon treatment with Triton X-100 detergent, the proteins within lipid rafts are retained, whereas non-raft domains are dissolved. B) A20 D1.3 B cells were transfected with raft-APEX2, lipid raft marker (DAT-GPI) or non-raft marker (TMD-GFP), and either activated (black bars) or not (grey bars) with 1 $\mu \mathrm{g} / \mathrm{ml} \mathrm{HEL}$ for $10 \mathrm{~min}$. The fluorescence of the markers was measured before and after subjecting the samples to $0.1 \%$ Triton X-100 for $5 \mathrm{~min}$, and the detergent resistance index was calculated. C) Related to the main Figure 1D and E. Raft-APEX2-expressing (Continued) 
Figure S1: (Continued) A20 D1.3 B cells and the parental A20 D1.3 (non-transfected) cells were treated with 0, $0.1,1$ and 10 mM $\mathrm{H}_{2} \mathrm{O}_{2}$, or $10 \mu \mathrm{g}$ anti-IgM F $\left(\mathrm{ab}^{\prime}\right)_{2}$ fragments. Cells were lysed and subjected to Western blotting. The membranes were probed with HRPanti phospho-Tyrosine antibodies, and anti $\beta$-actin as a loading control. D) Raft-APEX2 A20 D1.3 B cells were supplemented with biotin-phenol, activated (red line) or not with (violet line) $\mathrm{F}\left(\mathrm{ab}^{\prime}\right)_{2}$ fragments of anti-IgM antibodies for 5 min, and the biotinylation was triggered or not (grey line) by adding $1 \mathrm{mM} \mathrm{H}_{2} \mathrm{O}_{2}$ for $1 \mathrm{~min}$. Cells were fixed with $4 \%$ PFA, permeabilised, stained with AF-633-labelled streptavidin and analysed with flow cytometry.

A

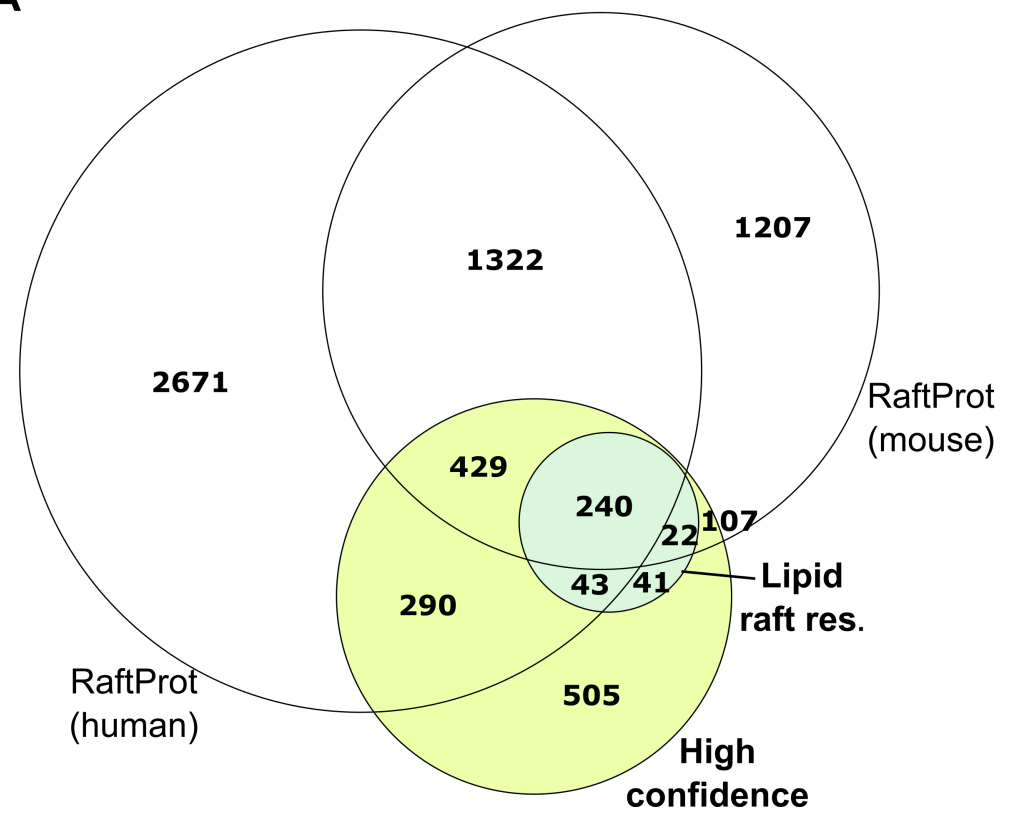

B

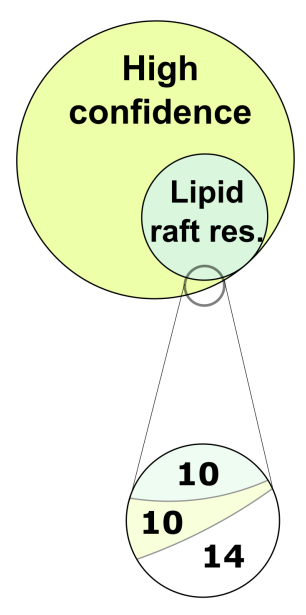

Saeki et al., 2003

(34)

\section{Proteins names}

ACTB GNAI3

CAPZB LSP1

10 EZRI RFTN1

GBB2 TBB5

GNAI2 VDAC2

CSK MYO1G

KC1G1 RALA

10 LYN SNP23

MYH9 US6NL*

MYO1C VDAC1

CD48 DRA/HA21

EFR3A NEP

FGR PALD

14 FLOT1 PHB2

FLOT2 PP1G

G3P SEM7A

GBB1 TBA1A

Figure S2: Lipid raft-resident proteins in B cells. Related to main Fig.3. A) A Venn diagram showing intersection between the data obtained in this study to both mouse and human raft proteins in RaftProt database. B) A Venn diagram showing intersection between the data obtained in this study to lipid raft proteins identified in Raji B cells by Saeki et al. (Saeki et al., 2003) 
bioRxiv preprint doi: https://doi.org/10.1101/2020.09.29.318766; this version posted March 5, 2021. The copyright holder for this preprint (which was not certified by peer review) is the author/funder, who has granted bioRxiv a license to display the preprint in perpetuity. It is made

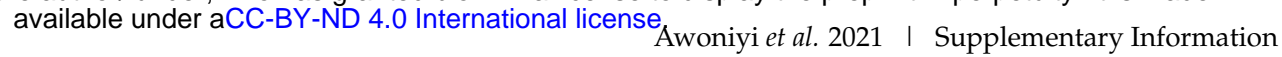

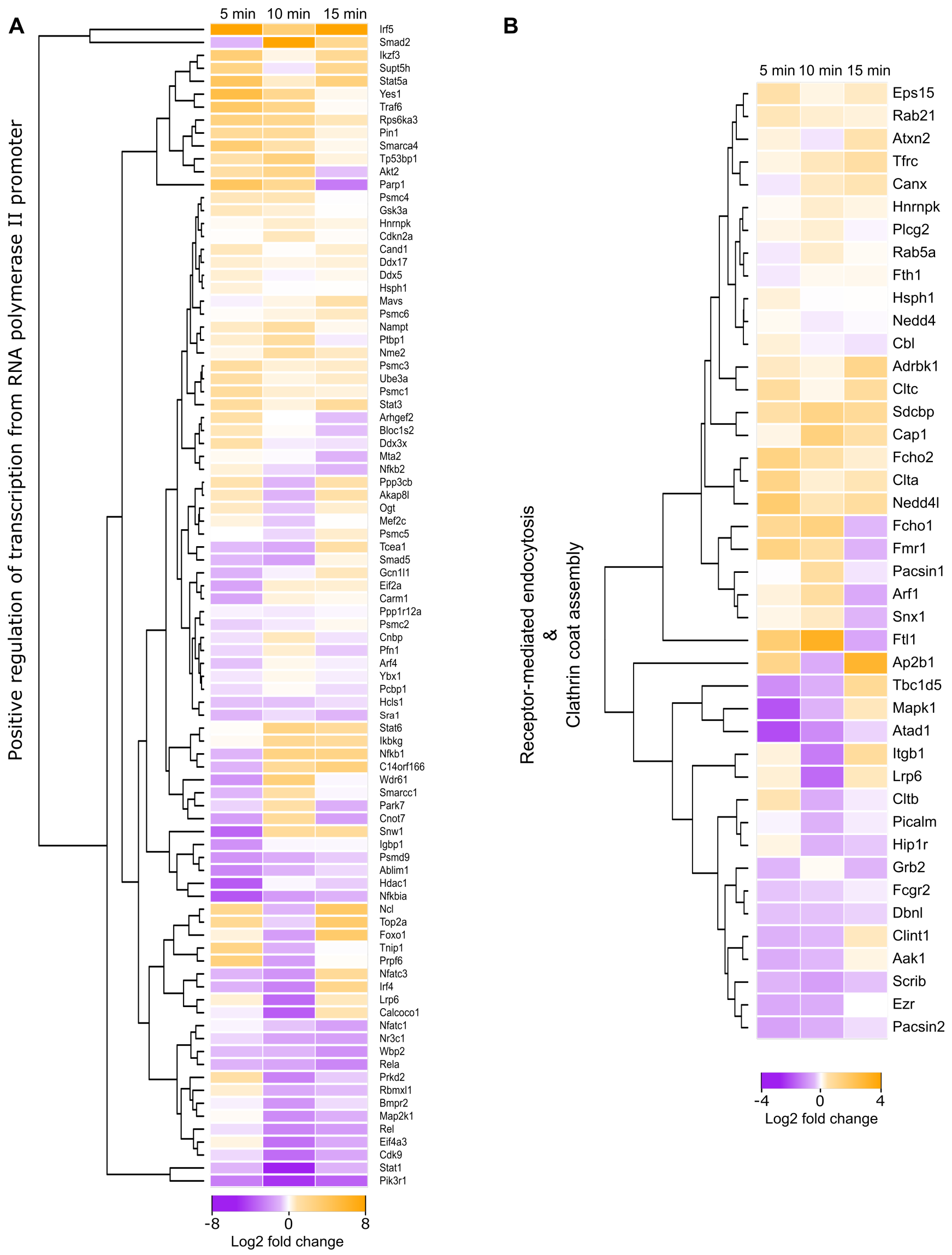

Figure S3: Heatmaps. A) Heatmap of the intensity changes of proteins with GO term "positive regulation of transcription from RNA polymerase II promoter". B) Heatmap of the intensity changes of proteins with GO term "receptor-mediated endocytosis" and "clathrin coat assembly". 
bioRxiv preprint doi: https://doi.org/10.1101/2020.09.29.318766; this version posted March 5, 2021. The copyright holder for this preprint (which was not certified by peer review) is the author/funder, who has granted bioRxiv a license to display the preprint in perpetuity. It is made available under aCC-BY-ND 4.0 International license.

A
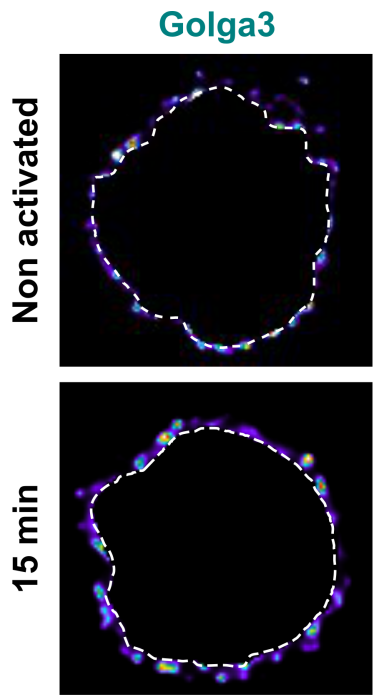

Antigen
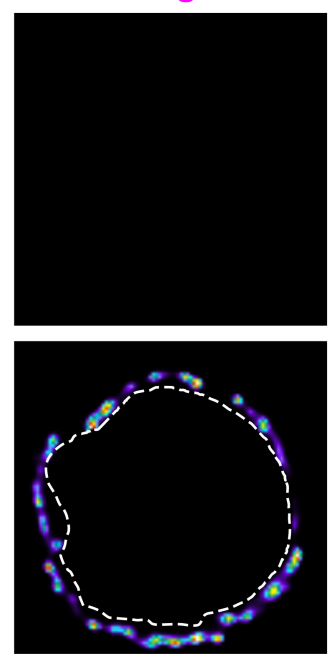

Merge
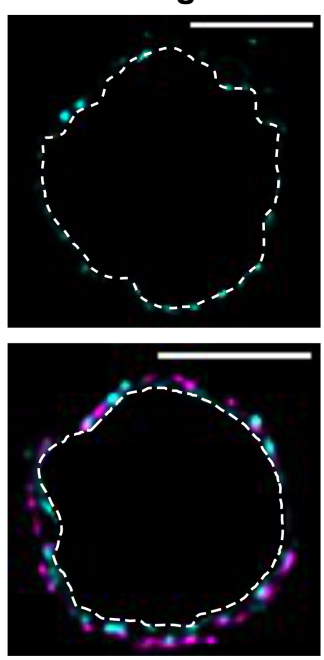

Supplementary Information

B

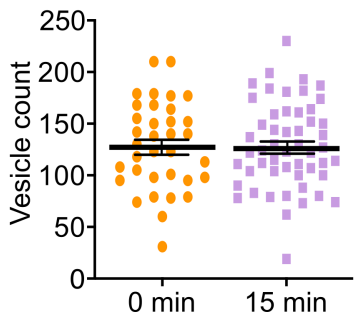

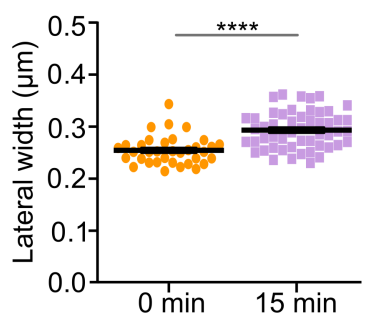
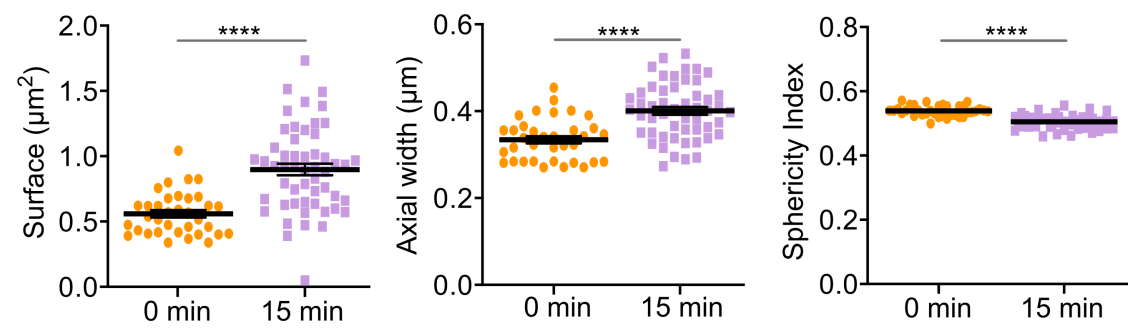

Figure S4: Golga3 particle analysis. Related to the main Fig.6 A,B. A) SDCM images of Raji D1.3 cells illustrating the thresholding to segment only the peripheral region of the cell. A 3D mask (dotted line) was generated from cytosolic tubulin signal and the inside region of the mask was cleared from signal in all channels. The resulting peripheral Golga3 signal was processed for 3D particle analysis as well as colocalisation analysis with antigen (AF647-anti-IgM F $\left.\left(\mathrm{ab}^{\prime}\right)_{2}\right)$. Single confocal planes from deconvoluted images of representative cells are shown. Scale bar $5 \mu \mathrm{m}$. B) Golga3 particle analysis in non-activated and activated Raji D1.3 cells was carried out with Huygens. The peripheral vesicle count per cell, lateral and axial width $(\mu \mathrm{m})$, sphericity index $(1=$ full sphere) and surface area $(\mu \mathrm{m} 2)$ are shown. Data shown as mean \pm SEM from $\geq 35$ cells from three independent experiments. ${ }^{* * *}: \mathrm{p}<0.0001$ 
bioRxiv preprint doi: https://doi.org/10.1101/2020.09.29.318766; this version posted March 5, 2021. The copyright holder for this preprint (which was not certified by peer review) is the author/funder, who has granted bioRxiv a license to display the preprint in perpetuity. It is made available under aCC-BY-ND 4.0 International license
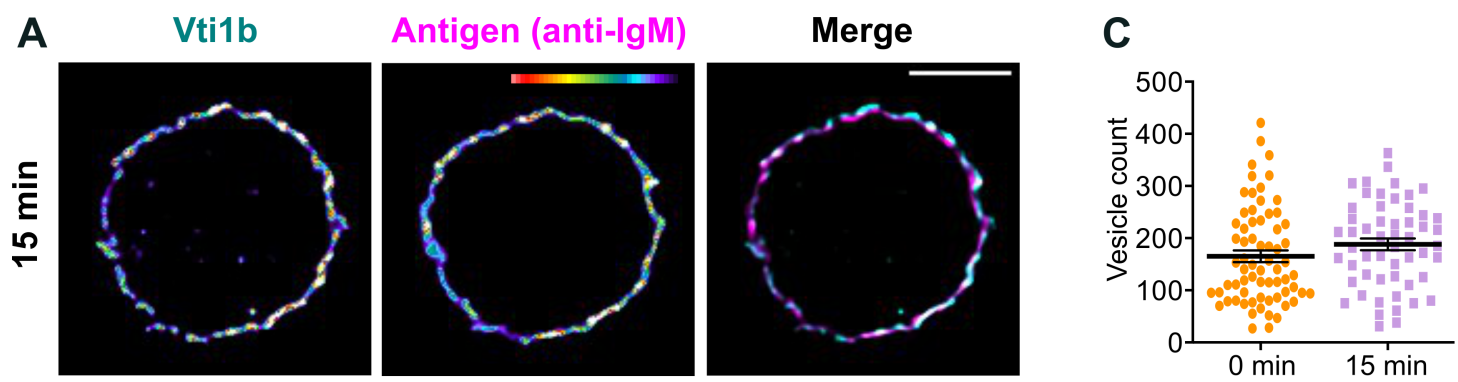

Supplementary Information
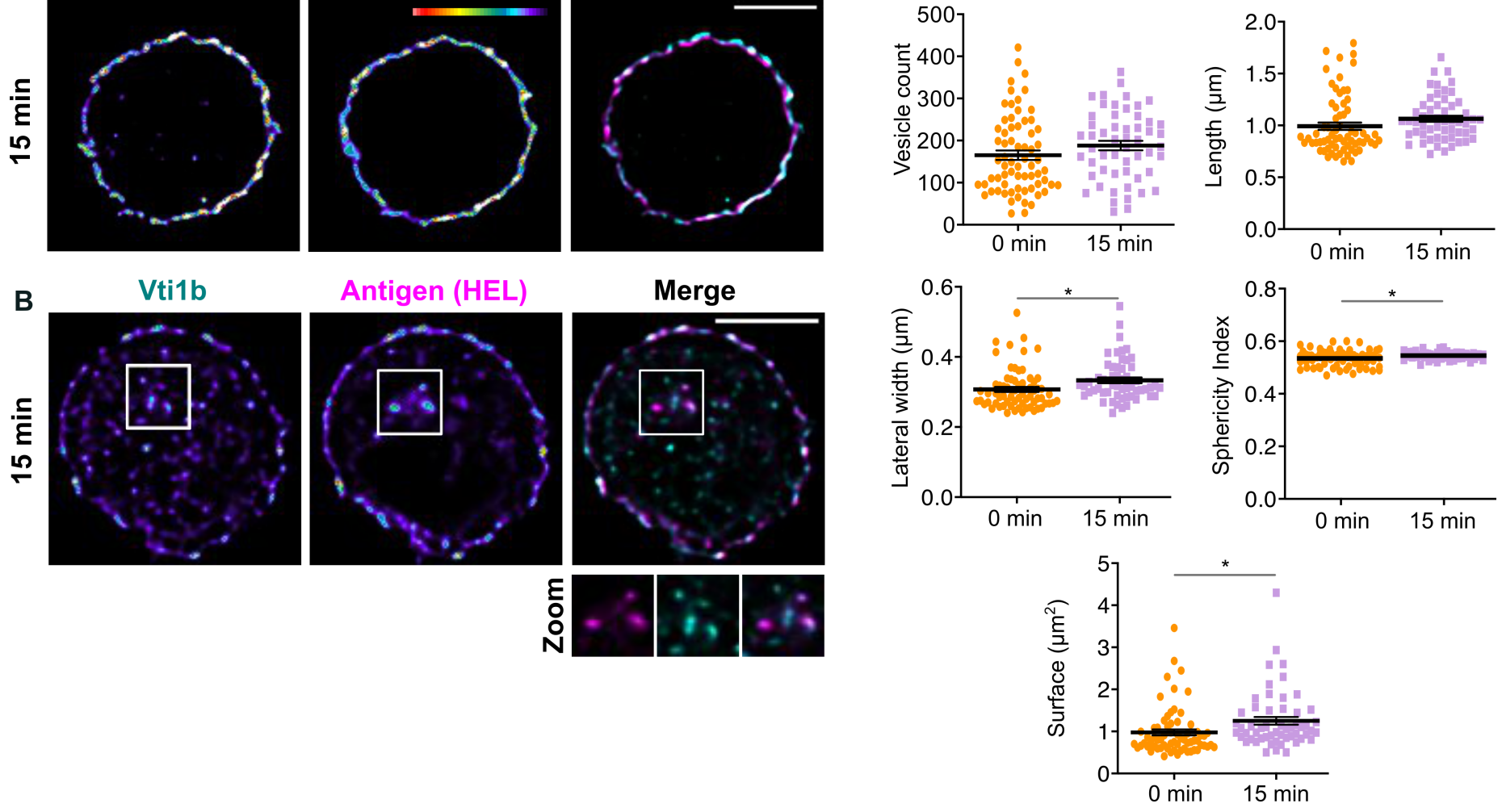

Figure S5: VTI1b translocation to the plasma membrane upon BCR signalling. Related to the main Fig.6 C,D. A-B) SDCM images of Raji D1.3 cells that were activated with $10 \mu \mathrm{g} / \mathrm{ml}$ of AF488-labelled F(ab') 2 fragments of anti-IgM (magenta) (A) or $5 \mu \mathrm{gg} / \mathrm{ml} \mathrm{HEL}$ (magenta) B) for $15 \mathrm{~min}$ and immunostained for VTI1b (cyan). The zoom-in images show partial colocalisation of the two channels in perinuclear regions. Single confocal planes from deconvoluted images of representative cells are shown. Scale bar $5 \mu \mathrm{m}$. C) VTI1b particles in non-activated and activated Raji D1.3 cells were analysed with Huygens. VTI1b vesicle count per cell, length and lateral width $(\mu \mathrm{m})$, sphericity index $(1=$ full sphere) and surface area $(\mu \mathrm{m} 2)$ are shown. Data shown as mean \pm SEM from $>50$ cells from three independent experiments. ${ }^{*}: \mathrm{p}<0.05$ 